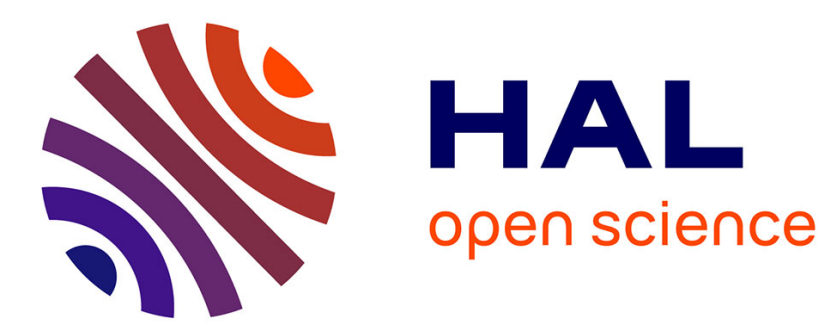

\title{
Heme ligation in the gas phase
}

Niloufar Shafizadeh, Benoît Soep, Maria Elisa Crestoni, Aurélien de La Lande

\section{To cite this version:}

Niloufar Shafizadeh, Benoît Soep, Maria Elisa Crestoni, Aurélien de La Lande. Heme ligation in the gas phase. International Reviews in Physical Chemistry, 2021, 40 (3), pp.365-404. 10.1080/0144235X.2021.1952006 . hal-03383675

\section{HAL Id: hal-03383675 https://hal.science/hal-03383675}

Submitted on 18 Oct 2021

HAL is a multi-disciplinary open access archive for the deposit and dissemination of scientific research documents, whether they are published or not. The documents may come from teaching and research institutions in France or abroad, or from public or private research centers.
L'archive ouverte pluridisciplinaire HAL, est destinée au dépôt et à la diffusion de documents scientifiques de niveau recherche, publiés ou non, émanant des établissements d'enseignement et de recherche français ou étrangers, des laboratoires publics ou privés. 


\title{
Heme ligation in the gas phase
}

Niloufar Shafizadeh ${ }^{\text {a*}}$, Maria Elisa Crestoni ${ }^{b}$, Aurélien de la Lande ${ }^{c}$ and Benoît Soep ${ }^{a}$

${ }^{a}$ ISMO, Université Paris Saclay, CNRS UMR 8214, bat 520, Université Paris Saclay 91405, Orsay Cedex, France

${ }^{b}$ Dipartimento di Chimica e Tecnologie del Farmaco, Università di Roma "La Sapienza", P.le A. Moro 5, 00185, Roma, Italy

${ }^{c}$ Institut de Chimie-Physique, Université Paris Saclay, CNRS, UMR 8000. 15, rue Jean Perrin, 91405 Orsay Cedex, France.

* Author for correspondance

\begin{abstract}
This review summarizes the state-of-the-art knowledge of heme ligation in the gas phase. The unique aspect of the gas phase approach is to allow a step-by-step ligation of heme and thus enable the analysis of the properties of -four, -five and -six coordinate hemes in vacuo, under conditions directly comparable with quantum calculations. This approach also allows the characterization of situations uncommon in Nature, completing the coordination spectrum of hemes: four coordinate heme and protonated heme, an intermediate between ferrous and ferric heme. Therefore, a complete set of systems is described for the ferrous and ferric cases and there is no discontinuity between the two oxidation states of iron, so that the same mechanisms are at work, donation and back donation of different strengths depending upon the ligand. The similarity of ligation properties in ferrous and ferric hemes is consistent with calculations of the electron density at the Fe atom level, rather independent of the formal oxidation state in contrast with the porphyrin cycle. Hemes spin states have been reviewed, for they identify the electronic distribution of the metal. In ligated ferrous and ferric hemes, we find that binding energy measurements combined with spectroscopy describe their properties most effectively.
\end{abstract}




\section{Introduction}

Heme species have the potential of ligating molecules and enabling the transport of dioxygen with hemoglobin in living systems. Hemes have long existed on Earth and participate to evolution, owing to their presence already 3.8 billion years ago in cyanobacteria for the production of molecular oxygen [1]. They belong to the family of metal porphyrins, easily formed by condensation of their pyrrole rings in tetra pyrroles [2]. Their endurance is such that they are even present in meteorites [3]. The family of porphyrins and their likes is unique and owes its prevalence in the plant and animal worlds not only to their stability but also to their multifaceted redox properties. Through the inclusion of a transition metal, they act as strong oxidants in ferric heme or as electron donors in ferrous heme. Nature relies on porphyrins and their likes for a wide variety of purposes, which differ in type but also in function: oxidation or reduction in cytochrome $c$, scavenging reactive oxygen species, notably $\mathrm{O}_{2}{ }^{-}$and $\mathrm{H}_{2} \mathrm{O}_{2}$ in mitochondria, electron transport in chlorophyll pairs of photosystem II, small molecules transport in hemoproteins.

The efficiency of dioxygen binding to hemoproteins has been studied over almost one hundred years and can be monitored by the pressure of dioxygen necessary to complex half of the available $\mathrm{Fe}$ atoms in heme, $p_{1 / 2}$. Even through myoglobin proteins, $p_{1 / 2}$ varies

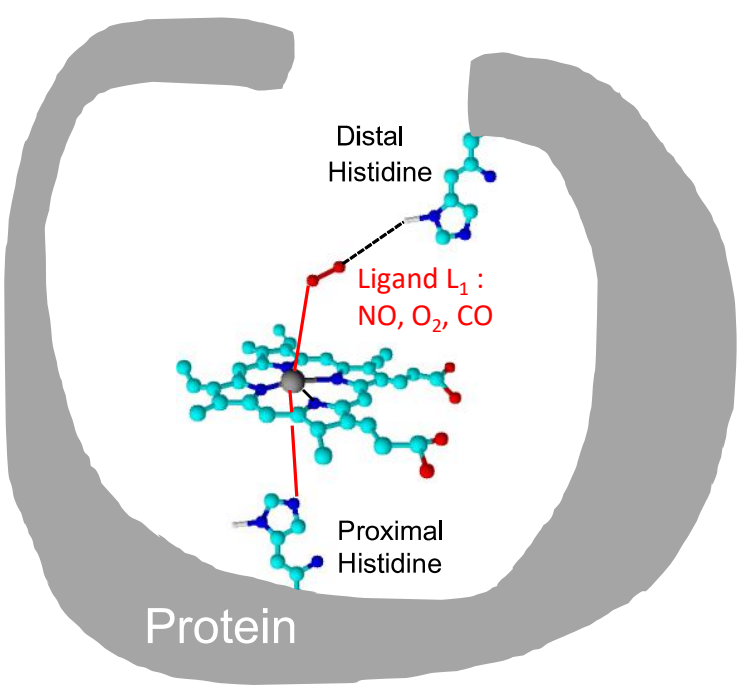

Figure 1: Schematics of heme interactions in hemoproteins with ligands in $5^{\text {th }}, 6^{\text {th }}$ coordination and protein. Ligand $\mathrm{L}_{1}$ also interacts with distal histidine.

between $\sim 0.002$ torr for the nematode Ascaris, $\sim 1$ torr for mammalian myoglobin $\mathrm{Mb}$ and up to $\sim 1000$ torr for acidic trout blood [4]. This difference in affinity by a factor of $5 \times 10^{5}$ may be converted into Gibbs free energy $\Delta G$ with $K_{p}=\exp \left(-\frac{\Delta G}{R T}\right)$, where $K_{p}$ is the equilibrium 
constant of the association reaction of $\mathrm{Mb}$ with dioxygen $\left(\mathrm{Mb}+\mathrm{O}_{2} \rightleftarrows \mathrm{MbO}_{2}\right)$. The resulting free energy difference between the two extreme cases $\Delta G_{2}-\Delta G_{1}$ amounts to $7.8 \mathrm{kcal} / \mathrm{mol}$. Binding energies, related by thermodynamics with free energies, are therefore precise markers of the affinity of ligands to hemoproteins.

The interaction of molecules with heme is extremely specific and directed as axial ligands on the central $\mathrm{Fe}$ atom, as shown in Figure 1. Herein, this review aims to individualize ligation events and add sequentially ligands in order to bring into evidence the separate interactions of ligands. If we examine the heme molecule embedded within the hemoprotein in Figure 1, the contact of the small ligand $L_{1}$ on a bare heme will be strong, meanwhile the attachment of heme with the proximal histidine will tune this initial bond strength, and the hydrogen bonding of $\mathrm{L}_{1}$ with the distal histidine may strengthen the $\mathrm{L}_{1}-\mathrm{Fe}$ interaction. Therefore, $\mathrm{L}_{1}$ binding to $\mathrm{Fe}$ heme is delicately modulated by several direct factors. Our intention is to scale directly these factors and to find a possible rationale, by measuring binding energies of $\mathrm{L}_{1}$ with or without an electron donating ligand in opposite coordination. It is also essential to study hemes with different oxidation states on the $\mathrm{Fe}$ atom in order to: i) monitor the evolution of $\mathrm{L}_{1}$ binding with the gradual change of the electron distribution on the Fe atom, through its $3 \mathrm{~d}$ orbital occupation; ii) elucidate the nature of the affinity of $\mathrm{L}_{1}$ for Fe. Moreover, when possible, it is essential to determine ligation energy values at constant $\mathrm{Fe}$ (3d) configuration (or at constant spin), in order to allow the interpretation of the effects of spin crossover on binding. Indeed, it is well known since the observations of Pauling that ligated oxyhemoglobin or carboxyhemoglobin are diamagnetic ( $S=0$ ) unlike deoxyhemoglobin, which is paramagnetic ( $S=2$ per unit) [5]. Furthermore, since ligands are often exchanged in Nature, like for example $\mathrm{CO}$ and $\mathrm{O}_{2}$, a ladder of binding energies can be directly obtained, thus quantifying ligand exchanges.

The study of the specific properties of heme-ligand bonds has been first performed in the condensed phase using tailored model systems, with the difficulty of avoiding side effects such as the permanent oxidation of the ferrous $\mathrm{Fe}$ atom by $\mathrm{O}_{2}$ in place of ligation. This binding approach was achieved on a few synthetic systems, where a reversible dioxygen fixation could be observed [6-8]. Gas phase measurements provide in turn the most direct means for the manipulation and energetic diagnosis of these bonds, also allowing a direct bonding / back bonding scheme that applies here and is supported by quantum chemistry, an effort pioneered by Praneeth et al."[9]. In a dual redox scheme, binding to heme is described as a $\sigma$ donation from the ligand to the $\mathrm{Fe}$ atom at the center of protoporphyrin IX, [Fe $\left.\mathrm{Fe}^{\mathrm{II}} \mathrm{Heme}\right]$, accompanied by a $\pi$ back donation to the ligated molecule. These contributions may vary in intensity 
depending on the oxidation state, the initial and/ or final spin states and of course on the number of ligands, either 5 or 6 . We shall limit our discussion to these effects and the prospect of their description by means of quantum calculations. The effect of distal ligands in proteins is beyond the scope of this review.

Ferrous and ferric hemoproteins have different affinities for ligands, if only to mention dioxygen, despite the fact that ferric and ferrous free hemes show the same level ordering of their binding $\mathrm{Fe}$ (3d) orbitals and of their spin states. Nevertheless, spin crossing is frequent for ferrous ligation. That occurrence combines favorably with the proximity of high and low spin states in 6 coordinated histidine ligated hemes, as stressed by Chen H. et al. [10]. This spin state proximity results from the small size of the Fe (3d) orbitals comparatively to the heme cage dimensions. This is at variance with larger orbitals in $4 \mathrm{~d}, 5 \mathrm{~d}$ transition metals. The adequate $\mathrm{Fe}(3 \mathrm{~d})$ orbital dimensions ensure the broad diversity of the possible functions of heme proteins through the versatility of the Fe Heme system.

\section{Methods}

The systems under investigation in this review are always ionic species, since only ions can be manipulated, selected, cooled and characterized by mass spectrometry. Typical experimental set-ups are detailed in refs [11-17]. The ions are prepared by electrospray, then selected, directed to and stored in small traps or in larger electron rings where they are cooled, observed and manipulated. The ligation of hemes is always easily mass controlled but, since the second ligand has an overall reduced affinity, the preparation of pentacoordinate hemes is comparatively simpler in the gas phase as compared to solution. Hexacoordinate adducts are obtained in the same manner but starting from solutions of pentacoordinate hemes.

The review is not limited to heme molecules only, but more generally it deals with $\mathrm{Fe}$ porphyrins, noted $[\mathrm{Fe} \mathrm{P}]$, that share the same environment about the $\mathrm{Fe}$ atom, i. e. a porphyrin structure of approximate $\mathrm{D}_{4 \mathrm{~h}}$ symmetry. For the sake of simplicity, many calculations are performed on Fe porphyrin and many experimental data concern substituted Fe porphyrins as a good approximation of heme complexes. However, depending on the oxidation state of the $\mathrm{Fe}$ atom within the porphyrin, the type of ions that can be produced by mass spectrometry (MS) differs. While ferric $\mathrm{Fe}^{\mathrm{III}}$ ions bear directly a positive charge (Figure $2 b$ ), ferrous $\mathrm{Fe}^{\mathrm{II}}$ porphyrins are globally neutral. Therefore, extra charges need to be provided to ferrous porphyrins at the periphery of the active Fe center. For example, the 4 negative charges borne by the sulfonato 
groups in Fe-tetrakis(4-sulfonatophenyl)porphyrin [Fe TPPS $]^{4-}$ (Figure 2a) are not delocalized over the porphyrin ring but kept isolated by tilted phenyl groups. Then, the negative charges do not affect the $\mathrm{Fe}^{\mathrm{II}}$ atom and the ensemble of $\mathrm{Fe}$ surrounded by the pyrrole nitrogen $(\mathrm{Np})$ atoms of the porphyrin core are totally neutral. A similar situation is found in protonated Fe-tetrakis (4-pyridyl) porphyrin, where the positive charge is isolated at the periphery of the tilted pyridyl ring.

a)

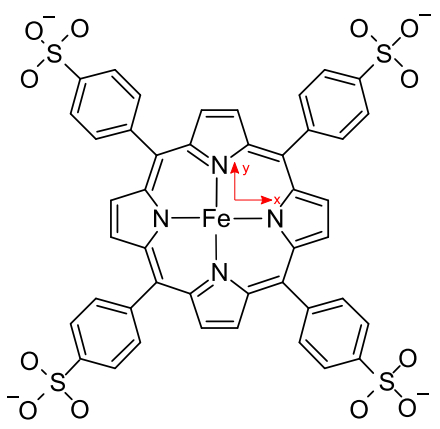

b)

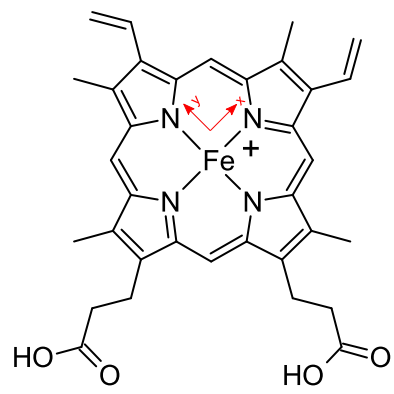

Figure 2: a) scheme of the $\mathrm{Fe}^{\mathrm{II}}$ tetrakis(4-sulfonatophenyl)porphyrin ( $\left[\mathrm{Fe}^{\mathrm{II}} \mathrm{TPPS}\right]^{4}$ ) quadruply charged anion, b) The $\left[\mathrm{Fe}^{\mathrm{III}} \text { protoporphyrin }\right]^{+}\left(\left[\mathrm{Fe}^{\mathrm{III}} \mathrm{Heme}\right]^{+}\right)$singly charged cation.

\subsection{Bond Energy determinations}

The experiments discussed in this review rely on a scheme elaborated by Dunbar [18] encompassing the properties of an ion trap, as described in Scheme 1. When in the trap, the metal porphyrin ion $\mathrm{P}^{+}$collides with ligand $\mathrm{L}$ with frequency $k[\mathrm{~L}]$, at the top of the centrifugal barrier, ligand $\mathrm{L}$ is captured at the distance where the charge attraction overcomes the centrifugal potential [19] ([L] concentration of ligand). Then, a [PL $]^{+*}$ complex is formed that can be stabilized from back dissociation with rate $k_{\text {diss, }}$, either by radiative emission with rate $k_{\mathrm{r}}$, or by collisions with the surrounding gas M (ligand + buffer gas), with rate $k[\mathrm{M}]$. In Dunbar's hypothesis, the unimolecular decay rate $k_{\text {diss }}$ of the $[\mathrm{PL}]^{+*}$ complex is much inferior to the radiative infrared emission rate $k_{\mathrm{r}}$ for this complex. Further, the pressure is taken sufficiently low that the total surrounding pressure quenching rate is lower than the radiative emission rate $k_{\mathrm{r}}$. At variance with the different experiments discussed here, the latter condition $k_{\mathrm{r}}>k[\mathrm{M}]$ can be reverted to the opposite where $k_{\mathrm{r}}<k[\mathrm{M}]$ and the background collisions stabilize the [PL] ${ }^{+*}$ complex instead of the radiative emission. 
Scheme 1: Dunbar's radiation association model

$$
\left[\mathrm{P}^{+}\right]+[\mathrm{L}] \underset{k_{\text {diss }}}{\stackrel{k[\mathrm{~L}]}{\rightleftarrows}}[\mathrm{PL}]^{+*} \underset{k[\mathrm{M}]}{\stackrel{k_{\mathrm{r}}}{\longrightarrow}}[\mathrm{PL}]^{+}
$$

The reaction rate of $[\mathrm{PL}]^{+}$formation can vary between values given by Langevin cross sections [20] or 1 - 2 orders of magnitude less [21]; however a thermodynamic equilibrium between $\left[\mathrm{P}^{+}\right]+[\mathrm{L}]$ and $[\mathrm{PL}]^{+}$can be established, depending on the forward association frequency $k[\mathrm{~L}](k$ is a gas kinetic constant) and the dissociation rate $k_{\text {diss. }}$ Note that with $k_{\text {diss }}$ described by RRKM (Rice-Ramsperger-Kassel-Marcus), the back reaction will be insomuch faster that the binding energy of $[\mathrm{PL}]^{+}$is small. In such case, this stems from a smaller density of bound states of $[\mathrm{PL}]^{+}$, relative to the sum of states for the active degrees of freedom at the transition state. Equilibrium conditions can be reached with a stabilisation of the ratio of the number density of $[\mathrm{PL}]^{+}$complexes to that of the reagents. The equilibration time varies strongly with the above parameters, from tens of seconds to tens of milliseconds.

Considering, for example, the ligation of NO to ferric heme, characterized by a very large binding energy for $\left[\mathrm{Fe}^{\mathrm{III}} \mathrm{Heme}-\mathrm{NO}\right]^{+}$, completion of the association equilibrium of $\left[\mathrm{Fe}^{\mathrm{III}} \mathrm{Heme}\right]^{+}$with $\mathrm{NO}$ reaches a maximum product formation in time (Figure 3 ). In turn, the mass-selected $\left[\mathrm{Fe}^{\mathrm{III}} \mathrm{Heme-NO}\right]^{+}$adduct decays to $\left[\mathrm{Fe}^{\mathrm{III}} \mathrm{Heme}\right]^{+}+\mathrm{NO}$ at room temperature with a reverse dissociation rate constant of $0.9 \cdot 10^{-3} \mathrm{~s}^{-1}[22]$. A global $\left[\mathrm{Fe}^{\mathrm{III}} \mathrm{Heme}\right]^{+}+[\mathrm{L}] \rightleftarrows\left[\mathrm{Fe}^{\mathrm{III}} \text { Heme-L }\right]^{+}$equilibrium is

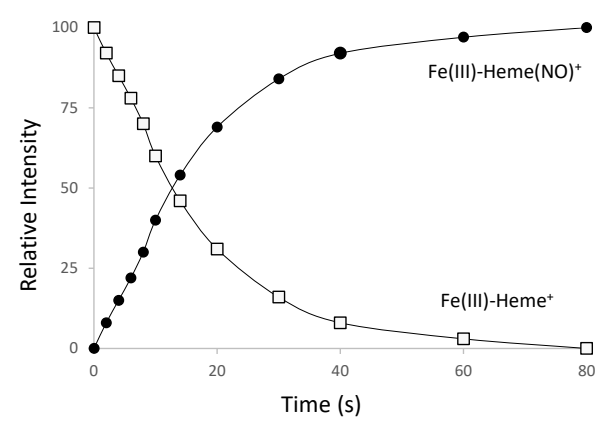

Figure 3 Time dependence of the relative ion abundances when $\left[\mathrm{Fe}^{\mathrm{III}} \text { Heme }\right]^{+}$ions, are allowed to react in the presence of 1.6 $10^{-7}$ mbar NO (from ref [13] with permission). thus obtained that can allow thermodynamic energy determinations. The thermodynamic data of the reaction can be recovered by several approaches, including reaction rate measurements, equilibrium concentrations measurements $[18,22]$, or van't Hoff temperature dependent enthalpy determinations $[17,23]$. Chen $\mathrm{O}$. et al. retrieved the binding energy from a complete modelling of the reaction rate including the dissociation rate of [PL]* as a function of its binding energy and the radiative emission rate [16]. Also, through kinetic measurements, the equilibrium constant $K_{\mathrm{p}}$ can be determined as the ratio of the forward and backward reaction rates, although it may be difficult to disentangle from secondary effects whenever the backward rate constant is low. On the other hand, provided that an equilibrium is reached, the equilibrium constant $K_{\mathrm{p}}$ value or its temperature dependence $\left(\frac{d \ln \left(K_{\mathrm{p}}\right)}{d T}=\frac{\Delta H_{r}}{R T^{2}}\right)$ yield respectively the Gibbs free energy $\Delta G$ or the reaction enthalpy $\Delta H$. The determination of $\Delta G$ is combined with an 
estimation of the entropy variation $\Delta S$ either by DFT calculations or by an evaluation of the freezing of the translational entropy through ligation (Sackur-Tetrode) [24]. Finally, ligand binding energies can be deduced from $\Delta H_{r}$ measurements as $\Delta H_{r}$ at $0 \mathrm{~K}$, assuming that the ligation process freezes the translation of $\mathrm{L}$, while the rotation of the ligand persists in its librations; the correction is therefore $3 / 2 R T$.

\section{2 spectroscopy of heme adducts}

Spectroscopy is a key tool to characterize the spin state of the ligated and unligated molecules in the gas phase, since Electron Paramagnetic Resonance is not accessible by lack of sensitivity. Either vibrational [25] or electronic [17, 26] "action" spectra are recorded by detection of the ligand loss. The depletion is intense and spectra are normalised by the total ion intensity prior to laser excitation obtained from $I_{[\mathrm{PL}]^{+}}+I_{[\mathrm{P}]^{+}}$. Vibrational spectra of ligated hemes are characteristic of a given spin for the heme system [25] similarly to electronic spectra. This evidence will be discussed in a dedicated paragraph.

Noteworthily, while the position of the bands in action spectra corresponds to the related absorption spectra, band intensities may be affected in two main ways: either through a wavelength dependent dissociation yield (1) or when the available internal energy of the ligated molecule is below the binding energy of the ligand (2). Case (1) is avoided with a weakly bound ligand that will dissociate uniformly at all wavelengths. In case (2), dissociation from a lower electronic state reached by electronic relaxation overcomes the energy balance requirements [14].

\subsection{Theoretical modelling}

Most properties of hemes have been modelled by theoretical chemistry. Structure modelling has been extremely successful since calculated structures in general reproduce within tenths of Ångström the X ray diffraction structures [27]. This is essential since the length of a Fe-Ligand bond and its spatial orientation relate to the electronic structure of the ligand bond, where for instance a $\pi$ donor will lead to a Fe-Ligand linear structure. Equally, force constants and vibrational frequencies are well determined by calculations for metalloporphyrins and hemes. The Fe-ligand bond strength is characterized through its stretch mode frequency and also that of its ligand modes. This analysis of the ligation is sensitive enough to allow a diagnosis and interpretation of the interactions of heme with its protein surroundings in hemoproteins [28]. Among the properties of interest in this review, the energetics as ligand binding energies and 
spin state energetics play a central role, since comparison can be made with experimental gas phase data. The states are characterized by their total spin, which is a combination of the spin of the Fe Heme moiety and that of the ligand. Here, we seek to obtain the local spin of Fe Heme that characterises its electronic configuration, the pertinent information.

Given the size of the heme molecule, DFT and its variants is the method of choice, capable of predicting correctly the spin state of the ground state of many systems containing transition metals. Moreover, it yields precise geometrical structures. Its precision regarding the energy determinations has however been questioned and the reasons for its deficiencies were analysed in details by several authors [10, 29-31]. Kohn-Sham DFT deals with exchange and correlation of electrons (XC) in an approximate fashion making the calculation of the electronic structure of low to high spin transition metals particularly delicate to achieve successfully. These difficulties are manifest in the scattering of binding energies for the Fe P-CO binding, spanning a factor of 2.5 depending on the chosen XC energy functionals [23]. However, Harvey [29] examined the detailed balance of the contributions in exchange and correlation such as the role of exact exchange introduced through HF (Hartree-Fock) calculations. This is reasonably balanced in hybrid functionals like B3LYP [32]. Progresses in multireference ab initio methods, (for instance the stochastic-CASSCF methods optimizing the use of the active space) have allowed comparisons with DFT for model porphyrins. However, despite the use of very large bases, the description of the high spin state is still incomplete with multi reference methods. Aside this important case, these multi reference methods are essential when accurate wave functions are needed : projection on valence bond orbitals [10] or transition moment calculations. In this perspective, DFT calculations executed with caution yield tremendously informative results often at more than semi-quantitative level and probably raise important questions when in internal disagreement or with experimental results.

Describing the bonding of ligands is conveniently imaged by charge movements, ligand donation and $\mathrm{Fe}$ atom back donation. It is interesting to model this reality although partial atomic charges are not physical observables. This is tentatively done by the iterative Hirshfeld procedure, or with Natural Orbitals. The latter method is appealing since these orbitals are the eigenfunctions of the density matrix and thus represent best the adequate charge density profile and its change through ligation [33]. 


\section{Spin Structure of Fe porphyrins}

The values of the spin of iron porphyrins reflect the electron occupation of the d orbitals of the central iron atom. This occupation also defines the affinity of the Fe atom towards ligands. Thus, it is essential to determine the nature of the spin for the $\mathrm{Fe}^{\mathrm{II}}, \mathrm{Fe}^{\mathrm{III}}$ ground states in the case of four-coordinate (free porphyrin), five and six-coordinate (ligated) porphyrins.

The iron porphyrin can exist, as shown in Figure 4, as low spin $(S=1 / 2, S=0)$, intermediate spin $(S=3 / 2, S=1)$ or high $\operatorname{spin}(S=5 / 2, S=2)$ depending on the oxidation state, either ferric or ferrous, of the $\mathrm{Fe}$ atom. In addition, for a specific cytochrome $\mathrm{C}^{\prime}$ containing $\mathrm{Fe}^{\mathrm{III}}$, a mixed spin state $(S=5 / 2,3 / 2)$ has also been observed [34].

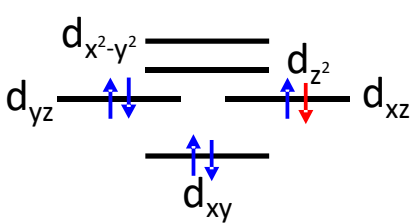

$$
\begin{array}{cc}
\text { Fe } & S=1 / 2 \\
\text { Fell } & S=0 \\
& \text { Low spin state }
\end{array}
$$

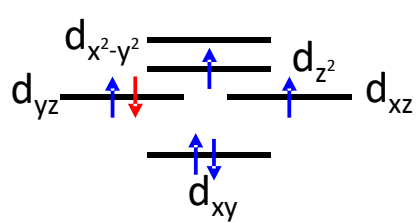

$$
S=3 / 2
$$$$
S=1
$$

Intermediate spin state

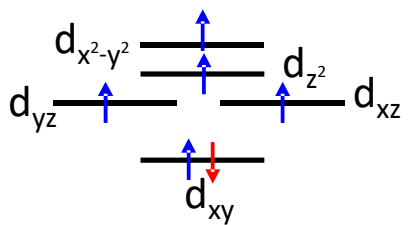

$$
S=5 / 2
$$$$
S=2
$$

High spin state

Figure 4: Preferential occupation scheme of $3 \mathrm{~d}$ orbitals for $\mathrm{Fe}^{\mathrm{III}}$ in blue and $\mathrm{Fe}^{\mathrm{II}}$ in red, for their different spin states in a tetragonal environment.

Figure 4 shows the preferential ordering of $\mathrm{Fe}(3 \mathrm{~d})$ orbitals in a tetragonal environment. It is subject to variations with porphyrin structure as we shall see, but is globally verified experimentally [34]. In each specific case, the precise ordering can be determined through the total state symmetry via magnetic measurements, but the different states usually lie in close proximity. The relative ordering of the $\mathrm{Fe}(3 \mathrm{~d})$ orbitals of iron porphyrins is influenced by deformations of the porphyrin ring: planar, ruffled, saddled or domed as sketched in Figure 5, using drawings from [35]. In the case of a ruffled configuration, meso-carbon atoms (carbon atoms linking the pyrrole rings, see Figure $2 b$ ) deviate from the mean porphyrin plane up and down alternatively. In the case of a saddled configuration,

$\beta-$ carbons deviate from the mean porphyrin plane.

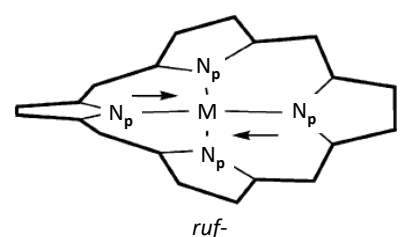

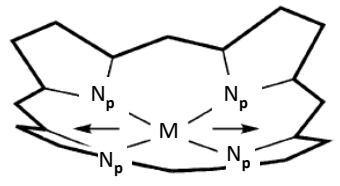

dom-

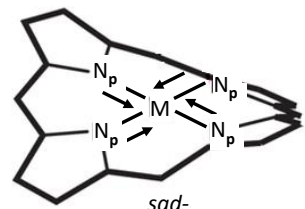

sad-

Figure 5: Relevant deformations of the porphyrin: cycle ruffling, doming, saddling. The movements Doming occurs when of the nitrogen atoms $\mathrm{Np}$ of the cage with respect to the metal $\mathrm{M}$ are displayed as arrows. Adapted the Fe atom sticks out from ref [35] with permission. 
of the average plane defined by the four nitrogen atoms $\mathrm{N}_{\mathrm{p}}$ of the porphyrin ring. The electronic configuration and the ordering of the Fe (3d) orbitals are determined by the extent of specific repulsion that the structure of the porphyrin cage exerts on them.

The Fe $\left(3 d_{x^{-y}}^{2}\right)$ orbital directed towards $\mathrm{Np}$ atoms is strongly repelled, while Fe $\left(3 \mathrm{~d}_{z^{2}}\right)$, with its in plane small corona of electron density facing these atoms, to a lesser extent. On the other hand, $F e\left(3 d_{\pi}\right)$ out of plane orbitals are less affected. This sets the occupation of the orbitals in absence of exchange correlation that stabilizes high spin states. Therefore in the spin state energetics, there is a balance between $\mathrm{Fe}(3 \mathrm{~d})$ electron repulsion by the cage and the occupation of higher energy levels through exchange correlation stabilisation. This balance will also involve cage deformations where, for instance, doming will level off the repulsion of the $\mathrm{Fe}$ $\left(3 d_{x}{ }^{2} y^{2}\right)$ orbital with the porphyrin cage and decrease the energy of high spin states.

Yan Ling et al. [36] showed that in planar and ruffled porphyrin complexes the $d_{x y}$ orbital is energetically situated below $d_{\pi}\left(d_{x y}<d_{\pi}\right)$ and the opposite occurs for the saddled configuration $\left(d_{x y}>d_{\pi}\right)$. The position of Fe $\left(3 d_{z^{2}}\right)$, according to this author [36], relies essentially on the cage structure and above a certain $\mathrm{Fe}-\mathrm{Np}$ distance it lies above $\mathrm{d}_{\pi}$ orbitals as in porphyrins in difference to phtalocyanins. Also, it was recently shown on an ensemble of synthetic five coordinate anionic $\mathrm{Fe}^{\mathrm{II}}$ porphyrins in high spin $S=2$, that the lowest $\mathrm{Fe}\left(3 \mathrm{~d}\right.$ ) orbital was of $\mathrm{d}_{\pi}$ symmetry [37].

Thus, the determination of spin states combines the experimental characterisation of the spin values and quantum chemistry calculations of spin state energies. Among gas phase chemical physics methods, X-ray Fe L edge spectroscopy could be an appropriate technique to provide direct information on the spin state of isolated iron porphyrins [38]. Indeed, the L edge lineshapes reflect the occupation of Fe (3d) orbitals in the ligand field of the porphyrin and are adequately modelled, yielding a spin state identification. So far X-Ray spectroscopy has rarely been used for the investigation of gas phase metalloporphyrins, because of the difficulty of coupling an evaporation source and synchrotron radiation. Other optical spectroscopies (UV, visible or infrared) cannot measure directly the spin state of the ground state molecules studied, but they provide decisive fingerprinting as detailed in paragraph 4.

Only condensed phase methods allow direct spin state identification, through the measurements of the total spin values. This allows the ordering of the Fe (3d) frontier orbitals. The two most direct methods are: EPR (Electron Paramagnetic Resonance) a method for studying the spin states by the measure of the resulting magnetic moment of the unpaired 
electrons, Mössbauer spectroscopy, has also been widely applied to iron-containing organometallic molecules or proteins. Indirectly, HNMR and ${ }^{13} \mathrm{CNMR}$ spectra allow the spin state determination of iron complexes and the relative ordering of the Fe (3d) orbitals. The interaction of iron $3 \mathrm{~d}$ electrons with the $\pi$ orbitals of the porphyrin macrocycle induces characteristic shifts in the HNMR and ${ }^{13}$ CNMR spectra of the pyrrole rings [6], which are modelled by quantum chemistry calculations [36]. However, the high and low spin states are best documented as they are most prevalent in the condensed phase, contrary to intermediate spin states.

Also, in the UV-Visible absorption spectra, the presence or absence of a charge transfer (CT) transition around $600 \mathrm{~nm}$ allows to discriminate between the low spin state (absence of CT band) and intermediate or high spin state (presence of CT band) [39]. CT transitions involve $\pi_{\text {porphyrin }} \rightarrow \mathrm{Fe}(3 \mathrm{~d})$ excitations and thus depend upon the population of low lying Fe (3d) orbitals, ultimately from the spin state. A survey of the experimental techniques for determining the spin states of inorganic compounds is detailed in reference [40]

Given the difficulty in characterizing the spin in ground state ferrous or ferric porphyrin complexes by experimental methods, quantum chemical calculations are very useful to provide reliable spin state predictions. In the last two decades, numerous theoretical reports have been devoted to this topic $[10,30,41-44]$. It turns out that in the case of DFT-type calculations, the lowest spin state and the splitting between different spin components are dependent on the exchange-correlation functional and the size of the basis sets chosen [30]. A functional suitable for one system does not perform equally well for other system(s) [45]. Overall, hybrid functionals predict the ground state in accord with multi reference calculations [29], however remain difficulties in the determination of high spin state energetics, which in $6^{\text {th }}$ coordination can lay close to the low spin state. Hybrid DFT give more than a qualitative description of the spin splittings and allow a quantification of the $3 \mathrm{~d}$ electron distribution landscape.

\subsection{Four-coordinate Iron porphyrins}

\subsubsection{Four-coordinate Ferrous porphyrins}

The HNMR spectra of ferrous four-coordinate octaethylporphyrin, deuteroporphyrin IX dimethylester, meso-tetraphenylporphin and meso-tetra( $\alpha \alpha \alpha \alpha$-o-pivalamidophenyl)porphin (the so-called 'picket fence' porphyrin) show that these paramagnetic complexes are in the same spin state, the intermediate state $S=1$ [46], in non-polar solvents. 


\subsubsection{Four-coordinate Ferric porphyrins}

In condensed phase it is very difficult to form the four-coordinate ferric porphyrin cation due to its high electrophilicity $\left[\mathrm{Fe}^{\mathrm{III}} \mathrm{P}\right]^{+}$and this cation will even coordinate arene solvents upon crystallization. Fang et al. [47] have isolated a purely four-coordinate $\mathrm{Fe}^{\mathrm{III}}$ porphyrin both in the solid state and in solution by combining steric and electronic factors to create a very sterically hindered bis-pocket siloxyl porphyrin in conjunction with a bulky and very weakly coordinating anion. The characterization of this bulky quasi isolated $\left[\mathrm{Fe}^{\mathrm{III}} \text { TipsiPP }\right]^{+}$ferric fourcoordinate porphyrin, both in solution and in the solid state yields a pure $S=3 / 2$ intermediate spin state for this quasi planar ferric porphyrin. The latter planar structure is obtained from diffraction studies. In turn, if a counter ion $\left(\mathrm{CF}_{3} \mathrm{SO}_{3}{ }^{-}\right)$is allowed to enter the siloxyl pocket protecting the porphyrin, the $\mathrm{Fe}$ atom bulges above the nitrogen pocket by $0.4 \AA$, while the spin state becomes mixed ( $S=3 / 2$ and $5 / 2)$ corresponding to a $F e\left(3 \mathrm{~d}_{z^{2}}\right)$ partial population.

\subsubsection{Protonated heme, four-coordinate}

Protonated heme $\left[\mathrm{Fe}^{(\mathrm{II})} \mathrm{HemeH}\right]^{+}$has been produced by collision-induced dissociation from insource electrospray ionization of microperoxidase (MP11 is a small synthetic enzyme derived from cytochrome C) by Chiavarino et al. [48]. DFT calculations indicate that its most stable isomer is protonated on the $\beta$ carbon atom of one peripheral vinyl group (Figure 6). The analysis of spin density distributions has shown an appreciable fraction of the spin located on the carbon atom of the protonated vinyl group, which acquires a radical character (Figure 6, right), while the other fraction of spin remains located on the iron atom. As a consequence, protonated heme can be described as a mixed ferrous $\left[\mathrm{Fe}^{\mathrm{II}} \mathrm{HemeH}\right]^{+}$and ferric $\left[\mathrm{Fe}^{\mathrm{III}} \mathrm{HemeH}\right]^{+}$ oxidation state. This ion is partially distonic with radical character building on carbon C6 inasmuch the $\mathrm{Fe}$ atom resembles more $\mathrm{Fe}^{\mathrm{III}}$.

A triplet spin state has been predicted to be the ground-state for four-coordinate $\left[\mathrm{Fe}^{(\mathrm{II})} \mathrm{HemeH}\right]^{+}$ [48]. To the best of our knowledge, there are no experimental determinations of the spin state of protonated heme. 
a)

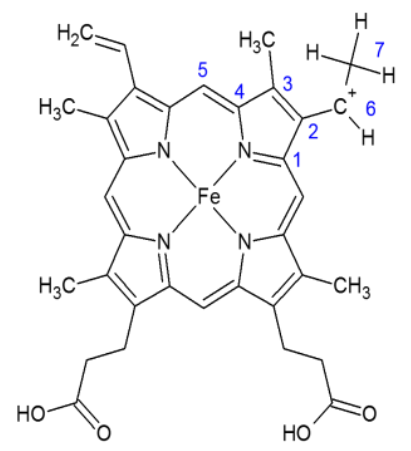

b)

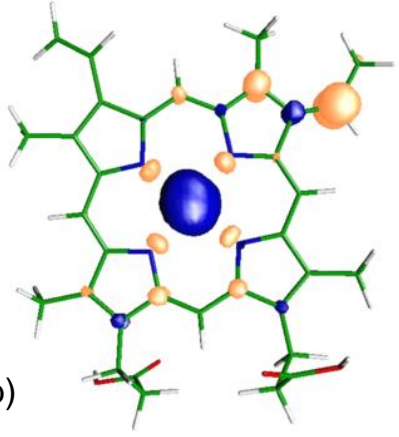

Figure 6: a) the most stable configuration of $\left[\mathrm{Fe}{ }^{\text {(II) }} \mathrm{HemeH}\right]^{+}$calculated by Chiavarino et al. [48]. The most stable location for the proton is on carbon $\mathrm{C} 7$. After addition of the proton on carbon $\mathrm{C} 7$, the $\mathrm{C} 6=\mathrm{C} 7$ double bond is opened and the positive charge is relocated formally on C6. b) spin distribution in this isomer. Blue regions denote excess $\alpha$ and yellow areas excess $\beta$ density. Adapted with permission from ref [48].

\subsection{Five- and six-coordinate Iron porphyrins}

When the iron porphyrin is axially ligated by one (five-coordinate) or two (six-coordinate) ligands, the ground state spin of the complex depends on the ligand field strength accompanied by the deformation of the porphyrin ring.

\subsubsection{Five-coordinate Ferric Porphyrins}

The five-coordinate complex of Fe $\mathrm{F}^{\mathrm{III}}$ porphyrin carrying an anionic ligand such as an halide or an acetate shows a high spin state, $S=5 / 2$ [49]. With a highly ruffled or saddled geometry, complexes adopt an intermediate spin state, $S=3 / 2$ [50] and the smaller cage structure of the five-coordinate chlorophatlocyanin, $\mathrm{Cl}^{-}$complex bears also $S=3 / 2 \operatorname{spin}[51]$. Notably, intermediate spin Fe porphyrins are rare in Nature [49] .

\subsubsection{Five-coordinate Ferrous Porphyrins}

Similarly to ferric 5-coordinate porphyrins, the spin of 5-coordinate ferrous porphyrins depends on the ligand field strength, i.e. for strong axial ligands, including $\mathrm{NO}$ and $\mathrm{CN}$, the complex is in the low spin state, whereas for weak ligands, such as imidazole or halides, the complex is in its high $\operatorname{spin} S=2[52]$.

\subsubsection{Five-coordinate protonated heme}

Adducts of protonated hemes bound to different small molecules, including $\mathrm{NO}$ [22], $\mathrm{O}_{2}$ [53], $\mathrm{H}_{2} \mathrm{O}$ [54], have been observed in ion traps. Calculations for [ $\left.\mathrm{Fe}^{(\mathrm{II})} \mathrm{HemeH}-\mathrm{L}\right]^{+}, \mathrm{L}=\mathrm{H}_{2} \mathrm{O}$ and $\mathrm{CO}$, 
are available, in both cases the spin state of the ground state is intermediate. In the case of NO, the calculation of the spin density distribution has shown that the complex ligated to NO ( low spin state) is stabilized by a charge transfer from $\mathrm{NO}$ to Fe, challenging the assignment of the formal metal oxidation state [22].

\subsubsection{Six-coordinate Ferrous and Ferric Porphyrins}

In the case of ferrous porphyrin complexes, the association of a ligand in the sixth position is often accompanied by a spin change, as in the case of $\left[\mathrm{Im}-\mathrm{Fe}^{\mathrm{II}} \mathrm{P}-\mathrm{O}_{2}\right],\left[\mathrm{Im}-\mathrm{Fe}^{\mathrm{II}} \mathrm{P}-\mathrm{CO}\right]$ or $\left[\mathrm{Fe}^{\mathrm{II}} \mathrm{P}-(\mathrm{Im})_{2}\right]$, that are all in a low spin state. The situation is however different for ferric complexes. Figure 7 shows an overview of the calculated energies of the spin states for free and ligated ferrous porphyrins ( Figure 7a) [30] and ferric porphyrins ( Figure 7b) [55], relative either to $\left[\mathrm{Fe}^{\mathrm{II}} \mathrm{P}\right]$ or to $\left[\mathrm{Fe}^{\mathrm{III}} \mathrm{P}\right]^{+}$. $\left[\mathrm{Fe}^{\mathrm{II}} \mathrm{P}-\mathrm{Im}\right]$ was positioned with respect to five coordinate $\left[\mathrm{Fe}^{\mathrm{II}} \mathrm{P}\right]$ using the binding energy of imidazole to $\left[\mathrm{Fe}^{\mathrm{II}} \mathrm{P}\right]$ calculated by Liao et al. [45] equal to $15 \mathrm{kcal} / \mathrm{mol}$. Since this calculated energy is very dependent on the DFT functional, we selected the highest binding energy using the PBEO/Tzp functional which agrees with a strong imidazole ligation with ferrous porphyrins.

For the ferrous porphyrin $(S=1)$ or $\left[\mathrm{Fe}^{\mathrm{II}} \mathrm{P}-\mathrm{Im}\right](S=2)$ complexes, ligation with $\mathrm{O}_{2}$ or $\mathrm{CO}$ is accompanied by a change to the ground state spin. Singlet states of both five- and six-coordinate complexes are found to have the lowest energy. Conversely, for ferric complexes, the ligation with $\mathrm{CO}$ or $\mathrm{O}_{2}$, both endowed with an intermediate strength ligand field, the spin state does not change. On the other hand, in the case of NO, with a strong ligand field, the ligand complex is always in the lowest spin state regardless of the oxidation state of the iron.
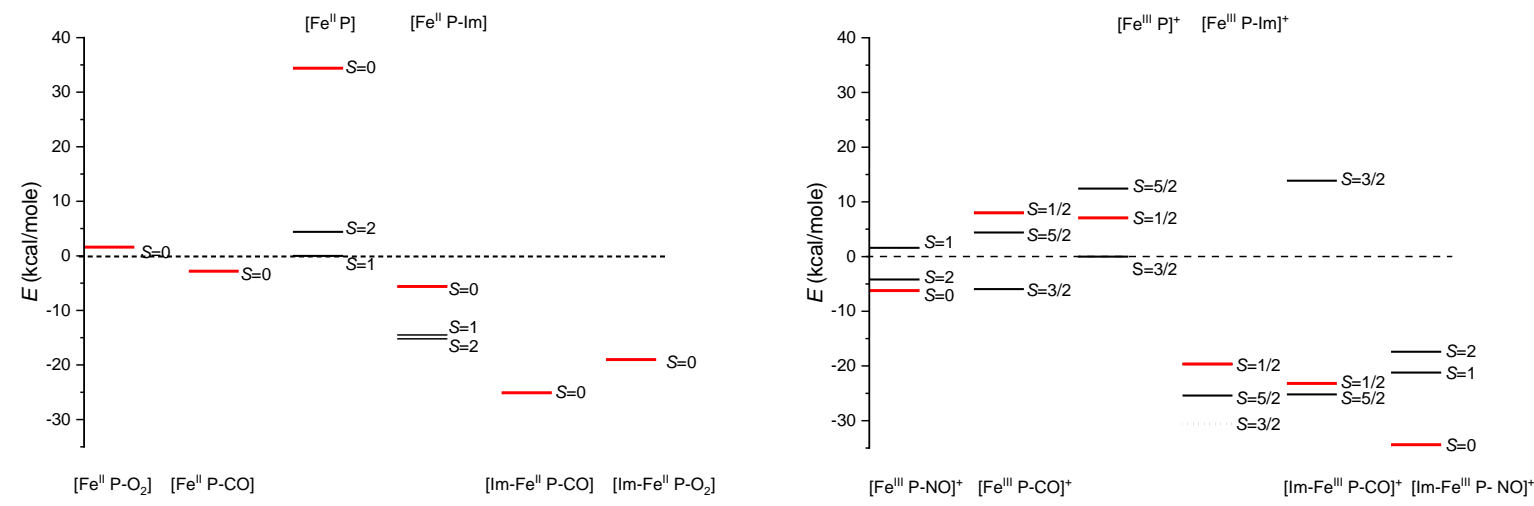

Figure 7: Overview of calculated relative energies $(\mathrm{kcal} / \mathrm{mol})$ of spin states for free and ligated ferrous porphyrin $\left[\mathrm{Fe}^{\mathrm{II}} \mathrm{P}\right]$ (Figure $7 \mathrm{a}$ ) and ferric porphyrin $\left[\mathrm{Fe}^{\mathrm{III}} \mathrm{P}\right]^{+}$(Figure $7 \mathrm{~b}$ ), given with respect to the lowest state of 4 coordinate iron porphyrin. The low spin states (ferrous $S=0$, ferric $S=1 / 2$, or 0 for NO) are drawn in red.

Figure $7 \mathrm{a}$, showing the data for ferrous porphyrin, is adapted from calculations by Radon and Pierloot [30] . [Fe ${ }^{\mathrm{II}} \mathrm{P}-$ $\mathrm{Im}]$ and $\left[\mathrm{Im}-\mathrm{Fe}^{\mathrm{II}} \mathrm{P}\right.$-Ligand] are positioned with respect to $\left[\mathrm{Fe}^{\mathrm{II}} \mathrm{P}\right]$ using the calculated binding energy of imidazole to iron Porphyrin $\left(E_{\text {bin }}=15 \mathrm{kcal} / \mathrm{mol}\right)$ [45] 
Figure $7 \mathrm{~b}$ shows the data for ferric porphyrin adapted from Aarabi at al. [55].

\subsubsection{Six-coordinate protonated heme}

To the best of our knowledge, there has been no observation of $\left[\mathrm{Im}-\mathrm{Fe}^{(\mathrm{II})} \mathrm{HemeH}-(\mathrm{L})\right]^{+}$in gas phase probably because of the harsh electrospray conditions adopted to produce protonated heme, preventing the formation of the covalent Hem-Im adduct.

\section{Spectroscopy of heme adducts}

\subsection{Electronic spectroscopy revealing spin states}

Eaton and Hochstrasser [56] carefully explored the spectroscopy of ferric myoglobin, a ferric five-coordinate hemoprotein, in oriented crystals in order to resolve and analyze its different vibronic bands in the visible domain. These bands may be classified in two groups, the $\pi$ electron system of the porphyrin ring and the mixed bands involving transitions between the metal atom levels and the $\pi$ system, called charge transfer bands. The polarizations of the transitions with respect to the crystal axes, i.e. the porphyrin planes, were also used for the identification of these bands. The authors varied the strength of the ligands coordinated to the Fe metal atom ion. A ligand exerting a strong electrostatic field over the Fe (3d) orbitals would largely split them and maximize the low spin state with electrons paired in the lowest orbitals. Indeed, the spectrum with ammonia, a medium strength ligand, presents solely porphyrin B (Soret) and Q bands corresponding to the promotion of respectively $\mathrm{a}_{1 \mathrm{u}}$ and $\mathrm{a}_{2 \mathrm{u}} \pi$ porphyrin orbitals $\left(D_{4 h}\right)$, to degenerate $e_{g}\left(\pi^{*}\right)$ orbitals symmetry. Conversely, with a weaker ligand as the fluoride ion, the opposite situation prevails and a high spin heme complex is formed. As a consequence, additional bands are observed in the red region (more conspicuously) above $600 \mathrm{~nm}$. The corresponding transitions can be assigned to electron promotion from porphyrin orbitals $\mathrm{a}_{1 \mathrm{u}}$ or $\mathrm{a}_{2 \mathrm{u}}$ to $\mathrm{Fe} 3 \mathrm{~d}_{\mathrm{xz}}, \mathrm{d}_{\mathrm{yz}}(\pi)$, in a charge transfer transition. The spin is characterized by its magnetic moment and uniquely identifies the orbital population in the present cases. Several ligands (fluoride, formiate) induce high spin configuration and it is interesting to note that, while the bands located on the porphyrin, B and Q remain at mostly constant wavelengths, the location of charge transfer bands is shifted with ligand strength, the strongest ligand having the largest blue shift. Electronic spectroscopy identifies low spin complexes unambiguously. However, since medium spin complexes also exhibit CT bands in the red spectrum, only additional measurements can discriminate the value of the spin on the metal as medium $(S=3 / 2)$ or high $(S=5 / 2)$. Nevertheless, the intensity of the charge transfer transitions is increased by the 
mixing of the porphyrin $\pi$ and $\mathrm{Fe}\left(3 \mathrm{~d}_{\pi}\right)$ orbitals, which is greater in the case of a medium spin ground state [31] as compared to high spin.

\subsubsection{Four-coordinate ferric porhyrins}

Four-coordinate ferric porphyrins are uncommon due to their positive charge attracting ligands and in Nature only cytochrome c' exists with a possible four coordination. While DFT calculations place four-coordinate ferric porphyrins in the medium spin state (see the preceding chapter), it has been difficult to isolate four-coordinate ferric porphyrins in solutions due to the attraction of negative counterions. Nevertheless, such a coordination was obtained by encapsulation of the ferric porphyrin with bulky substituents isolating the $\mathrm{Fe}^{\mathrm{III}}$ atom from the voluminous carborane counter-anion [47]. The measured magnetic moment $\mu_{s}=4.1 \mu_{B}$ allowed characterizing the intermediate spin of the porphyrin as $\mathrm{S}=3 / 2$, with $\mu_{s}=$ $\mu_{B} \sqrt{S(S+1)}=3.8 \mu_{B}$, while the visible spectrum showed a broad extra charge transfer band beyond the porphyrin in the $650 \mathrm{~nm}$ wavelength domain (Figure 8, red line). This evidence proves that spectroscopy can serve as a precise tool for the spin labeling in heme complexes and allows to verify the persistence of spin states upon ligation.

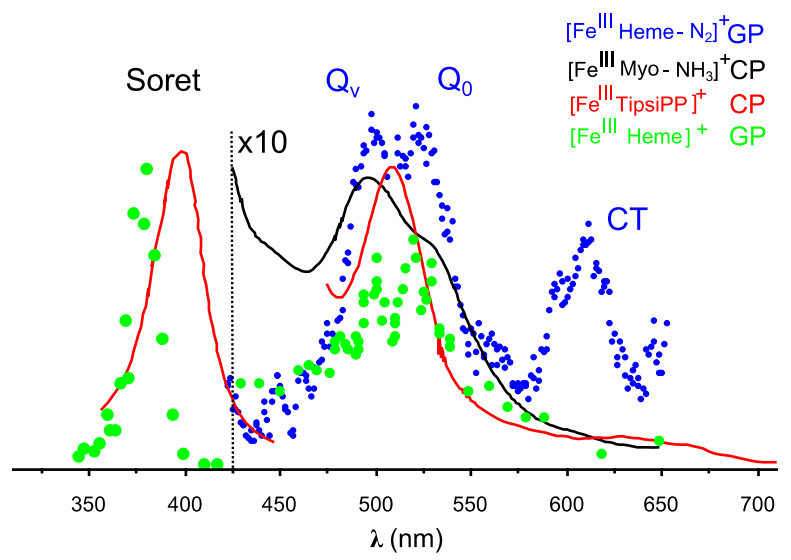

Figure 8 Action spectra of $\left[\mathrm{Fe}^{\mathrm{III}} \mathrm{Heme}-\mathrm{N}_{2}\right]^{+}$at $\mathrm{T}_{\text {trap }}=22 \mathrm{~K}$ (blue dots) The $\mathrm{Q}_{0}$ and $\mathrm{Q}_{\mathrm{v}}$ bands are situated at 525 and $497 \mathrm{~nm}$ respectively while the charge transfer $(\mathrm{CT})$ band appears at $610 \mathrm{~nm}$, typical of the high or intermediate spin configuration of iron in $\left[\mathrm{Fe}^{\mathrm{III}} \mathrm{Heme}^{+}\right.$, adapted from ref [17]. MetMyoglobin with $\mathrm{NH}_{3}$ (black line) is taken from ref [56] and blue shifted by $30 \mathrm{~nm}$. The Soret bands of $\left[\mathrm{Fe}^{\mathrm{III}} \mathrm{TipsiPP}\right]^{+}$(red) and [ $\left.\mathrm{Fe}^{\mathrm{III}} \mathrm{Heme}\right]^{+}$(green dots+Q bands) are adapted respectively from [47] and [57]. GP stands for gas phase, CP for condensed phase.

\subsubsection{Low spin ferric hemes}

Wyer and Nielsen [58] reported spectra of ferric hemes complexed with $\mathrm{NO},\left[\mathrm{Fe}^{\mathrm{III}} \mathrm{Heme}-\mathrm{NO}\right]^{+}$ at room temperature that exhibit two bands at 561 and $523 \mathrm{~nm}$ in the $400-600 \mathrm{~nm}$ region (blue 
dots in Figure 9). The main band of this five coordinated adduct can be assigned to the $\mathrm{Q}_{0}$ origin transition $(561 \mathrm{~nm})$ from its position and the fact that it is the first intense band. The second weaker one corresponds to vibrational excitation at $523 \mathrm{~nm}$. A similar spectrum has been observed at lower temperatures

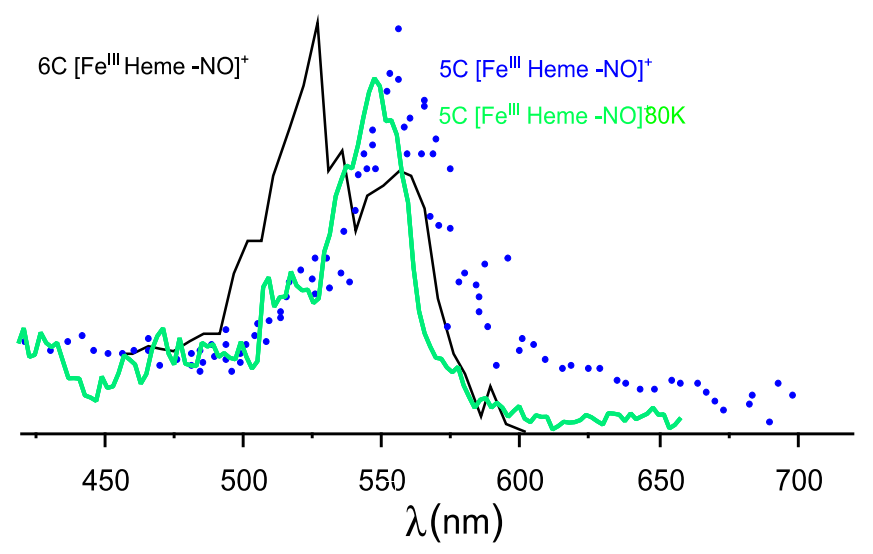

Figure 9 Action spectra of $5 \mathrm{C}\left[\mathrm{Fe}^{\mathrm{III}} \mathrm{Heme}-\mathrm{NO}\right]^{+}$at room temperature adapted from ref[58] (blue dots), at $80 \mathrm{~K}$ (green) and 6C $\left[\text { met-Fe }{ }^{\mathrm{III}} \mathrm{Heme}-\mathrm{NO}\right]^{+}$, (met=methionine) adapted from ref[58], with permission, in black.

at $80 \mathrm{~K}$, with bands narrower by $10 \%$ and blue shifted by $9 \mathrm{~nm}$ (Figure 9 , green line). Owing to the very short lifetimes of the levels reached in the B and Q transitions in metalloporphyrins that induce broad and diffuse bands, the spectra are not expected to narrow significantly at lower temperatures. Therefore, specific effects due to $6^{\text {th }}$ ligation can be identified in the spectrum of $\left[\mathrm{met}-\mathrm{Fe}^{\mathrm{III}} \mathrm{Heme}-\mathrm{NO}\right]^{+}$(met=methionine) in Figure 9 (black line). Strikingly, it keeps its main two bands at the same positions but with different intensity ratios. In the case of these two five- and six-coordinate nitrosyl ferric hemes, there is a characteristic absence of charge transfer bands in the red region of the spectrum $(>600 \mathrm{~nm})$, related to porphyrin $\pi \rightarrow \mathrm{Fe}\left(3 \mathrm{~d}_{\mathrm{xz}, \mathrm{yz}}\right) \mathrm{CT}$ transitions. These 'simple' spectra match the low spin ones presented for myoglobin with an ammonia ligand [56] in Figure 8, black line. It also agrees with the binding mechanism of NO with ferric heme leading to a low spin $S=0$ complex, amply discussed by Praneeth et al."[59]. Further on, we shall see the implications of the spin value of ferric heme on the NO binding.

\subsubsection{Medium spin ferric hemes}

Medium spin is characteristic of isolated 4-coordinate ferric heme, as exposed earlier. Its spectrum can be obtained by monitoring the loss of products by photodissociation, in general heme substituent propionic groups [26]. As shown in Figure 8 (green dots), its intense Soret band at $370 \mathrm{~nm}$ appears blue shifted with respect to the spectrum of the four-coordinate 
porphyrin reference solution in the $S=3 / 2$ state (red line). This intense porphyrin band is followed to the red of the spectrum by the $\mathrm{Q}$ bands, about ten times lower in intensity.

Ferric heme spectra can also be monitored by tagging with a very weak ligand [60], the ligand loss causing only a very minor structural change to heme. As an example dinitrogen binds only by $140 \mathrm{~cm}^{-1}$ to ferric heme [17]. The $\left[\mathrm{Fe}^{\mathrm{III}} \text { Heme- } \mathrm{N}_{2}\right]^{+*}$ complex quickly deactivates electronically to a lower state [61] and loses $\mathrm{N}_{2}$, allowing detection of the photofragment ion $\left[\mathrm{Fe}^{\mathrm{III}} \mathrm{Heme}\right]^{+}$with unit yield throughout the spectrum. An action spectrum paralleling the absorption spectrum is obtained by excitation in the 410-700 nm range, with only a slight $\mathrm{N}_{2}$ solvent shift caused by the ground state / excited state ion $\left[\mathrm{Fe}^{\mathrm{III}} \mathrm{Heme}-\mathrm{N}_{2}\right]^{+}$binding energy difference. One should note as in Figure 8 (blue dots), that its bands are broad even at low temperatures $(22 \mathrm{~K})$, consistent with the ultrashort excited state Q band lifetime of hemin as measured in the condensed phase [37].

The spectrum of $\left[\mathrm{Fe}^{\mathrm{III}} \text { Heme- } \mathrm{N}_{2}\right]^{+}$, shown in Figure 8 (blue dots) from $410 \mathrm{~nm}$ to $650 \mathrm{~nm}$, is composed of two broad structures: one envelope centered at $510 \mathrm{~nm}$, the other at $605 \mathrm{~nm}$. The $510 \mathrm{~nm}$ group is in the spectral region of the well-known porphyrin type vibronic $\mathrm{Q}_{\mathrm{v}}\left(\pi \pi^{*}\right)$ transitions shown for the $S=0$ nitrosyl complex in Figure 9, and for low spin ferric myoglobins [56] in Figure 8 (black line). The $\mathrm{Q}$ band splits in two maxima at $497 \mathrm{~nm}\left(\mathrm{Q}_{\mathrm{v}}\right)$ and $525 \mathrm{~nm}$ $\left(\mathrm{Q}_{0}\right)$, distant by $\sim 1070 \mathrm{~cm}^{-1}$.

For comparison, the absorption spectrum of low spin ferric myoglobin complexes measured in crystals is reported in Figure 8 (black line) showing two bands due to the vibrationally excited $\mathrm{Q}_{\mathrm{v}}$ and the origin transition $\mathrm{Q}_{0}[56]$. The intensity of the $\mathrm{Q}_{\mathrm{v}}$ band originates from the intense Soret band (at $370 \mathrm{~nm}$ ) through vibronic coupling. It is obvious that the $\mathrm{Q}$ bands of the low spin myoglobin match with those of $\left[\mathrm{Fe}^{\mathrm{III}} \mathrm{Heme}-\mathrm{N}_{2}\right]^{+}$after blue shifting by $30 \mathrm{~nm}$ for the protein effect. This group of bands close to $500 \mathrm{~nm}$ can be considered as a characteristic feature of heme Q absorption regardless of spin states, as they persist in high spin hemes [56].

The second main band (CT band) at $610 \mathrm{~nm}$ represents a spectral signature of the electronic configuration of the iron atom. In the $\left[\mathrm{Fe}^{\mathrm{III}} \mathrm{Heme}-\mathrm{N}_{2}\right]^{+}$complex, the position of the $610 \mathrm{~nm}$ band is similar to that observed at $\sim 630 \mathrm{~nm}$ in solutions of the four-coordinate $\left[\mathrm{Fe}^{\mathrm{III}} \text { TipsiPP }\right]^{+}\left[\mathrm{CB}_{11} \mathrm{H}_{6} \mathrm{Br}_{6}\right]^{-}$(TipsiPP stands for bis-pocket Siloxylporphyrin) [47] assigned as a medium spin ferric complex (in Figure 8 red line). The bands in the red and far red region $(>600 \mathrm{~nm})$ have been assigned to charge transfer transitions $(C T), a b_{2 u}(\pi) \rightarrow F e\left(3 d_{x z}, d_{y z}\right)$ transition. CT bands are detectable in the $400-600 \mathrm{~nm}$ spectrum, but are difficult to disentangle from other bands. Also, CT bands beyond $700 \mathrm{~nm}$ are generally less intense [62]. Indeed, in the 
observation of IRMPD signals of the $\left[\mathrm{Fe}^{\mathrm{III}} \mathrm{Heme}-\mathrm{N}_{2}\right]^{+}$complex, broad bands in the $3000 \mathrm{~nm}$ region have been tentatively assigned to electronic transitions of the complex, thus to low lying CT transitions [25].

\subsubsection{Dioxygen complexes}

Dioxygen complexes have been monitored by action spectroscopy at $60 \mathrm{~K}$, detecting the free deoxy four-coordinate $\left[\mathrm{Fe}^{\mathrm{III}} \mathrm{Heme}\right]^{+}$fragment ion [17]. As illustrated in Figure 10, the Q bands and CT band positions of the $\left[\mathrm{Fe}^{\mathrm{III}} \mathrm{Heme}-\mathrm{O}_{2}\right]^{+}$spectrum are essentially the same as for the nitrogen complex. The nitrogen heme complex can be considered as the reference to the free ferric heme $\left[\mathrm{Fe}^{\mathrm{III}} \mathrm{Heme}\right]^{+}$medium spin complex. The only difference between the CT bands of the $\left[\mathrm{Fe}^{\mathrm{III}} \mathrm{Heme}-\mathrm{O}_{2}\right]^{+}$and $\left[\mathrm{Fe}^{\mathrm{III}} \mathrm{Heme}-\mathrm{N}_{2}\right]^{+}$complexes is the change in their relative intensity with respect to $\mathrm{Q}$ bands, the oxygen complex losing half of its CT band intensity with respect to the nitrogen complex. The overall identity of the double banded spectra in both complexes leads to the conclusion that they pertain to the same spin species, that of medium spin fourcoordinate free ferric heme. Thus, complexation with $\mathrm{O}_{2}$ is affected without any heme spin change. As will be illustrated later, the spin pairing of $\mathrm{O}_{2}(S=1)$ and ferric heme $(S=3 / 2)$ leads to an $S=5 / 2$ total spin for the lowest energy state.

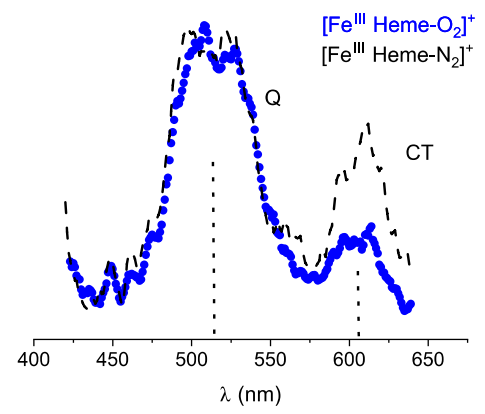

Figure 10; Action spectra of $\left[\mathrm{Fe}^{\mathrm{III}} \mathrm{Heme}-\mathrm{O}_{2}\right]^{+}$(blue dots) and $\left[\mathrm{Fe}^{\mathrm{III}} \mathrm{Heme}-\mathrm{N}_{2}\right]^{+}$(dashed black line). The dotted vertical lines indicate the centers of the $\mathrm{Q}$ and $\mathrm{CT}$ bands at respectively 510 and $610 \mathrm{~nm}$, adapted with permission from ref [17]. 


\subsubsection{High spin ferric hemes}

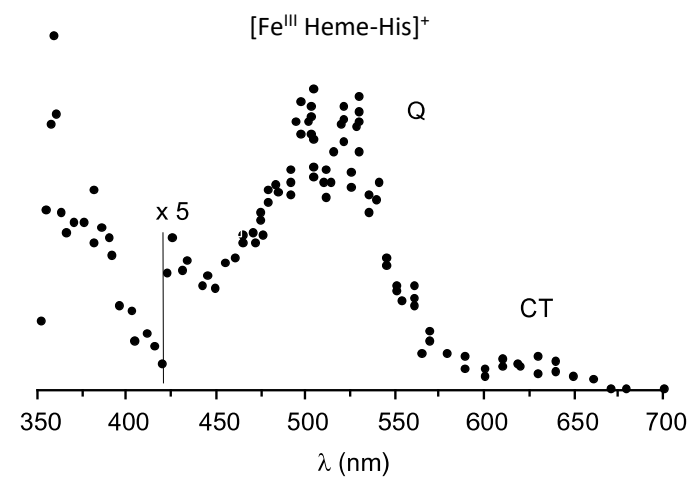

Figure 11: spectrum of [Fe $\left.{ }^{\mathrm{III}} \mathrm{Heme-His}\right]^{+}$adapted with permission from refs [63] and [26].

Five-coordinate high spin $(S=5 / 2)$ ferric hemes are obtained from efficient $\sigma$ donors, such as histidine. A spectrum is represented in Figure 11 with an intense Soret band blue shifted at $\approx 370 \mathrm{~nm}, \mathrm{Q}_{\mathrm{v}}$ and $\mathrm{Q}_{0}$ splitted $\mathrm{Q}$ bands at $500 \mathrm{~nm}$ and a weak CT band at $630 \mathrm{~nm}$, likely indicative of a high spin state. Ogoshi et al. note [64] that the Soret band is blue shifted in high spin porphyrins. The high spin state of the equivalent $\mathrm{Fe}^{\mathrm{III}}$ octaethylporphyrin imidazole complex was established by Scheidt et al.[65] through its high magnetic moment (5.9 $\mu_{\mathrm{B}}$, compared to $5.9 \mu_{\mathrm{B}}$ for $S=5 / 2$ ) and its domed structure with the Fe atom swelling out of the average plane of the Np atoms by $0.36 \AA$, a characteristic feature of high spin porphyrins.

\subsection{Vibrational spectroscopy of heme adducts}

In a series of experiments at low temperatures $(20 \mathrm{~K})$ the group of Niedner-Schattenburg observed mono ligated ferric complexes [Fe $\left.{ }^{\mathrm{III}} \mathrm{Heme}-\mathrm{L}\right]^{+}$with $\mathrm{L}=\mathrm{O}_{2}, \mathrm{CO}, \mathrm{N}_{2}$ as ligand. They obtained high precision vibrational spectra, well resolved in the $1000-2400 \mathrm{~cm}^{-1}$ spectral range [25]. Surprisingly, the spectra bear many similarities and allow to draw several conclusions on the detailed structure of the complexes. In this region, the most intense bands lying at 1740 and $1700 \mathrm{~cm}^{-1}$ correspond to the symmetric and antisymmetric stretching modes of the carboxylic groups. However, there are no observable transitions expected at $\mathrm{OH}$ groups on the carboxylic acids. This implies that the $\mathrm{OH}$ bonds form stable double hydrogen bonds, as shown in Figure 12 for the mono CO complex. This interpretation is in line with DFT calculations carried out with the B3LYP XC energy functional using 6-31+G* basis set. Calculations favor the present "cis" configuration with the ligands pointing towards the double $\mathrm{H}$ bonded groups for all the 3 mono-complexes, over the "trans",

with the benefit of $0.7 \mathrm{kcal} / \mathrm{mol}$ (Figure 12). 


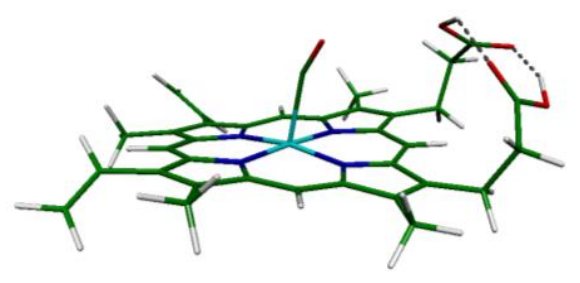

Figure 12: structure of the $\left[\mathrm{Fe}^{\mathrm{III}} \mathrm{Heme}-\mathrm{CO}\right]^{+} S=3 / 2$, from ref [55] with permission .

The close similarity of the spectra for the three ligands imply similar electronic structures and geometries. Modelling of the infrared spectra yields unambiguously the electronic structure with the spectra perfectly fitting those obtained with the local intermediate spin ferric heme, in difference with modelling for the other spin values. The latter are also higher in energy and not populated. For the oxygen complex, the total spin of the complex is $S=5 / 2$, combining the dioxygen spin. It was verified that $\left[\mathrm{Fe}^{\mathrm{III}} \mathrm{Heme}-\mathrm{O}_{2}\right]^{+}$comprises 3 unpaired $\mathrm{e}-$ on $\mathrm{Fe}^{3+}$ and 2 unpaired $\mathrm{e}-$ on $\mathrm{O}_{2}$ thus corresponding to the same local ferric heme medium spin.

As seen in spectra of Figure 13, none of the bindings leads to spin change and all complexes are most stable in the medium spin like free ferric heme. It appears that the $\mathrm{CO}$ stretch frequency is increased by $42 \mathrm{~cm}^{-1}$ from the free $\mathrm{CO}$ value sketched by a red line at $2143 \mathrm{~cm}^{-1}$. The calculated frequency is also increased for complexed $\mathrm{CO}$, as shown in the second curve (from top) of Figure 13 with a blue shifted frequency in the complex. Similarly, the stretching frequency of the NO ligand has also been determined in the five coordinate $\left[\mathrm{Fe}^{\mathrm{III}} \mathrm{Heme}-\mathrm{NO}\right]^{+}$ complex [66] [67] at $1842 \mathrm{~cm}^{-1}$, to be compared with a $1876 \mathrm{~cm}^{-1}$ for the free NO stretch. In the latter system, however, complexation occurs with a change of spin on heme, free ferric heme being medium spin, while NO complexed ferric heme is low spin as previously discussed and identified on the electronic spectra. We shall discuss later the change in NO frequency by complexation on the six-coordinate $\left[\mathrm{MI}-\mathrm{Fe}^{\mathrm{III}} \mathrm{Heme-NO}\right]^{+}(\mathrm{MI}=$ methyl imidazole $)$ where the NO frequency shift is more dramatic especially in view of the Fe ${ }^{\mathrm{III}}-\mathrm{NO}$ interaction. 


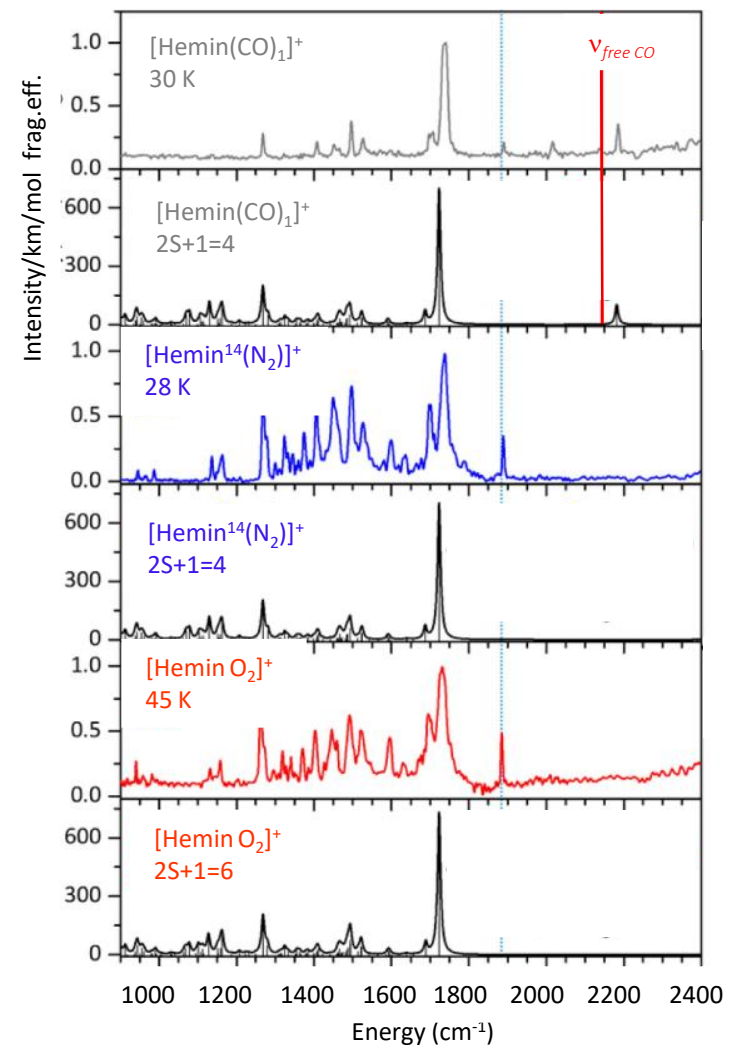

Figure 13: IR spectra of monoligated ferric heme. From top to bottom, $\mathrm{CO}$ complex, quantum chemistry simulation, $\mathrm{N}_{2}$ complex, QC simulation, $\mathrm{O}_{2}$ complex and simulation, adapted from ref [25] with permission.

Overall, infrared detection with the focusing of the measurements on local bonds allows fine details determinations of the frequencies of local modes.

\subsection{Models of the electronic spectra}

Gouterman developed a model by to rationalize the salient aspects of the spectroscopy of porphyrins using in Hückel theory, 4 delocalized $\pi$ orbitals in $D_{4 h}$ symmetry [68] and combining with atomic orbitals of the metal at the center of the ring $[69,70]$. His approach allows a description of the optical spectra in terms of $\pi \pi^{*}$ transitions porphyrin centered and charge transfer $\pi \rightarrow \mathrm{d}$ transitions, where excitation leads to placing porphyrin electrons into metal $\mathrm{d}$ orbitals. We have used above this reasoning to describe the global features of the actual spectra, and, if we put them in perspective, they allow a fingerprinting of the spectra for the spin values of central $\mathrm{Fe}$ atom.

However, this distinction between pure porphyrin centered and sheer charge transfer transitions fades since the Fe atom is $\sim 2 \AA$ separated from the neighboring Np atoms of the porphyrin cage. The orbitals of adequate symmetry $\mathrm{Fe}\left(3 \mathrm{~d}_{\mathrm{xz}}, 3 \mathrm{~d}_{\mathrm{yz}}\right)$ can mix with the porphyrin orbitals and this 
delocalization yields an increased intensity in the resulting spectra, neither pure porphyrin nor metal centered. Typically this is revealed in present calculations using DFT [71], TimeDependent DFT [72], where molecular orbitals are mixed to varying degrees. In these conditions, one may wonder whether it is still possible to describe the spectra in the previous terms as $\pi \pi^{*}$ and CT spectra? The answer is yes to gain a qualitative understanding on the nature of the levels.

-TDDFT (Time Dependent Density Functionnal) calculations can adequately describe the spectra, since they show as major bands in Figure 14, the group of transitions at $370 \mathrm{~nm}$, the Soret band typical of heme and at $500 \mathrm{~nm}$ the $\mathrm{Q}$ bands typical of low spin $(S=0)$ complexes like $\left[\mathrm{Fe}^{\mathrm{III}} \mathrm{Heme}-\mathrm{NO}\right]^{+}$shown in Figure 9.

-TDDFT modelling of spectra for complexes of increasing binding energy in the intermediate spin (3/2) for $\mathrm{Fe}^{\mathrm{III}}$ hemes, $\mathrm{N}_{2} \mathrm{H}_{2} \mathrm{O}$ and $\mathrm{CO}$ complexes, show that the $500 \mathrm{~nm} \mathrm{Q}$ band is still prominent (Figure 14). These calculations allow a semi-quantitative description of the visible transitions in ferric hemes complexes as originating from porphyrin $\pi \pi^{*}$ excitation.
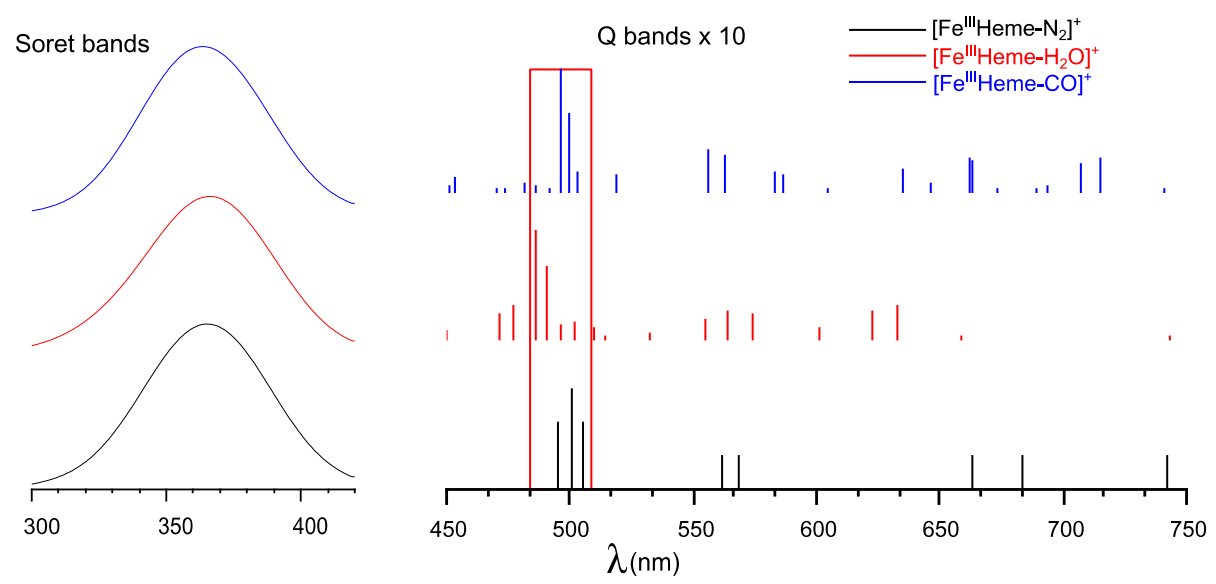

Figure 14: Calculated spectra in ferric heme for $\mathrm{N}_{2}, \mathrm{CO}$ and $\mathrm{H}_{2} \mathrm{O}$ complexes adapted with permission from ref [54] ESI.

The orbital description of the energy levels involved in the $503 \mathrm{~nm}$ transition localizes in majority on the porphyrin ring $\pi$ system in ground and excited states, as described in Figure 15. A completely different description prevails for the bands beyond $600 \mathrm{~nm}$, which are almost essentially $\pi \rightarrow \mathrm{Fe}$ (3d) and thus can be labeled as charge transfer. These bands however do not match the position of the experimental $610 \mathrm{~nm}$ band. 
$503 \mathrm{~nm}$

HOMO-1 $\rightarrow$ LUMO+3 $26.7 \%$
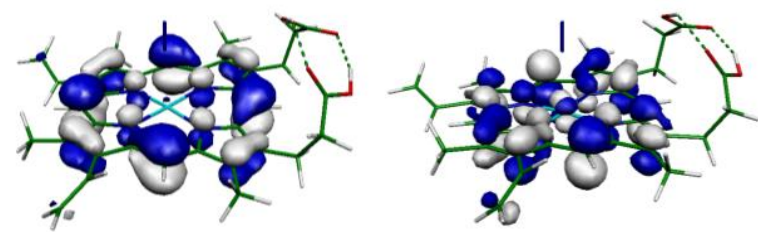

$\mathrm{HOMO} \rightarrow \mathrm{LUMO}+4 \quad 26.0 \%$
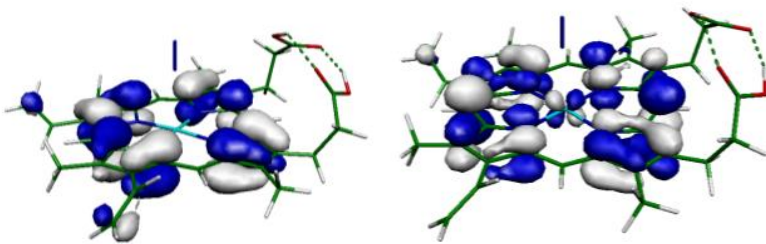

Figure 15: description of the major orbitals (left ground state right excited state) involved in the $503 \mathrm{~nm}$ band of [Fe ${ }^{\mathrm{III}} \mathrm{Heme}^{-}$ $\left.\mathrm{N}_{2}\right]^{+}$, adapted with permission from ref [55].

\section{The Fe-NO bond epitomic of ligation to heme}

Binding of NO to metalloporphyrins has a special importance because of the wealth of results obtained for a variety of systems including ferrous [73] and ferric [74] porphyrins in the condensed phase [75-77] and in the gas phase[13, 16, 22, 48] . It typifies well the advantages for single bond specific studies in the gas phase that allow direct measurements and direct comparison with conclusive calculations.

\subsubsection{Five-Coordination in NO complexes}

Chen O. et al. [16] were to the best of our knowledge, the first to obtain bond energies for a variety of Fe porphyrins with NO in five-coordination, while no formation of six-coordinate dinitrosyl complexes could be observed. In Chen O.'s experiments, the energy of the Fe-NO bond in $\mathrm{Fe}^{\mathrm{II}}$ protonated tetrapyridylporphyrin $\left[\mathrm{Fe}^{\mathrm{II}} \mathrm{TPyrPH}-\mathrm{NO}\right]^{+}$could be measured by simulation of the kinetics of the radiative association/dissociation along the method of Dunbar[18], yielding $E_{\mathrm{FeII}-\mathrm{NO}}=26.6 \pm 0.7 \mathrm{kcal} / \mathrm{mol}$. The remarkable NO binding properties are shared by ferrous porphyrins ions and by both $\left[\mathrm{Fe}^{(\mathrm{II})} \mathrm{HemeH}\right]^{+}$and $\left[\mathrm{Fe}^{\mathrm{III}} \mathrm{Heme}\right]^{+}$ions $[16,22]$. Relevant kinetic and thermodynamic parameters for NO binding are collected in Table 1 where a comprehensive picture of the kinetics and equilibrium data is presented [19]. 
Table 1: Kinetics and Equilibrium Data for NO Binding to $\left[\mathrm{Fe}^{(\mathrm{II})} \mathrm{HemeH}\right]^{+}$and $\left[\mathrm{Fe}^{\mathrm{III}} \mathrm{Heme}\right]^{+}$ions in the gas phase. $\boldsymbol{k}_{f}$ kinetic constant for the association of NO to the heme ion at $300 \mathrm{~K}, \boldsymbol{k}_{r}$ reverse rate constant for the association of NO to the heme ions, in $\mathrm{s}^{-1}$, at $300 \mathrm{~K}$. $\boldsymbol{K}$ Equilibrium constant for the association of NO to the heme ions at $300 \mathrm{~K}$, adapted from Ref [22].

\begin{tabular}{ccccc}
\hline Reactant ion & $\begin{array}{c}k_{f} / 10^{-11} \mathrm{~cm}^{3} \\
\text { molecule }\end{array}$ & $\begin{array}{c}k_{r} / \\
10^{-3} \mathrm{~s}^{-1}\end{array}$ & $\begin{array}{c}K / \\
10^{11} \mathrm{~atm}^{-1}\end{array}$ & $\begin{array}{c}\Delta G / \\
\mathrm{kcal} / \mathrm{mol}\end{array}$ \\
\hline$\left[\mathrm{Fe}^{\mathrm{III}} \mathrm{Heme}\right]^{+}$ & 2.2 & 0.9 & 5.3 & 16.1 \\
{$\left[\mathrm{Fe}^{(\mathrm{II})} \mathrm{HemeH}\right]^{+}$} & 3.3 & 0.8 & 5.7 & 16.1 \\
\hline
\end{tabular}

Notably, a unified pattern emerges from the closely similar kinetic and thermodynamic parameters in the gas phase reaction of $\mathrm{NO}$ with four coordinate iron $\left(\mathrm{Fe}^{(\mathrm{II})} \mathrm{H} / \mathrm{Fe}^{\mathrm{III}}\right)$ heme ions at $300 \mathrm{~K}$. With an entropy loss for NO binding $\left(\Delta S=-45.4 \mathrm{cal} \cdot \mathrm{K}^{-1} \cdot \mathrm{mol}^{-1}\right)$, binding energies values of $29 \mathrm{kcal} / \mathrm{mol}$ are obtained, close to Chen O.'s values for $\mathrm{Fe}^{\mathrm{II}}$ ions. Noteworthily, these comparable data relate to direct gas phase ligation with four-coordinate heme in difference with values for ferrous porphyrins in solution, where binding appears far stronger than for the equivalent ferric complexes [76].

The energy of the Fe-NO bond in five coordination, for either the ferrous and ferric model porphyrins, has been quite extensively calculated $[22,30,78]$ and it is always very important for a heme complex. For the ferrous porphyrin, Radon et al. [30] obtain $\Delta E_{\text {bond }}=41$ and $67 \mathrm{kcal} / \mathrm{mol}$ with the B3LYP DFT functional and CASPT2 methods, respectively. Fundamentally, this large ligation energy also involves spin crossing with passage from [Fe $\mathrm{P}]$ $(S=1)+\mathrm{NO}(S=1 / 2)$ to $\left[\mathrm{Fe}^{\mathrm{II}} \mathrm{P}-\mathrm{NO}\right]$ with the total spin calculated as $S=1 / 2$ from spin density [30, 79].

The calculations yield a conclusive picture for ferrous model porphyrin Fe-NO binding in five coordination. The orbital picture is depicted in Figure 16 and reveals the highest occupied orbital of the complex as a bonding combination, $\pi_{\mathrm{h}}{ }^{*}, \mathrm{~d}_{\mathrm{z}^{2}}$ (h=horizontal, NO $\pi^{*}$ orbital in the $\mathrm{Fe}-\mathrm{N}-\mathrm{O}$ plane $)[9]$. There, the empty $\mathrm{Fe}\left(3 \mathrm{~d}_{z^{2}}\right)$ orbital of low-spin $\left[\mathrm{Fe}^{\mathrm{II}} \mathrm{P}-\mathrm{NO}\right]$ strongly $\sigma$ binds the singly occupied $\pi^{*}$ orbital of NO, resulting in an even distribution of this unpaired electron density of $\mathrm{NO}$ over the $\mathrm{Fe}-\mathrm{N}-\mathrm{O}$ unit. The calculated spin densities of about $50 \%$ on iron and $50 \%$ on NO support this description. 


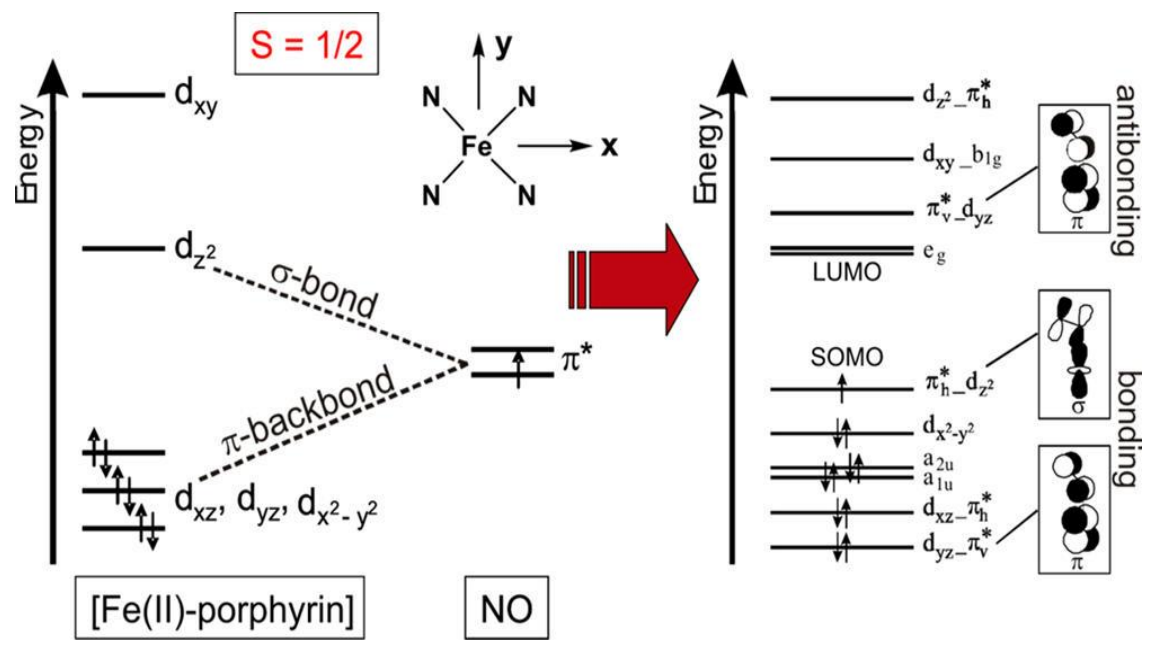

Figure 16: scheme of the calculated electron occupations of $\left[\mathrm{Fe}^{\mathrm{II}} \mathrm{P}-\mathrm{NO}\right]$ (right) and their origin (left). Note that the x,y axes labeling is $45^{\circ}$ rotated from Figure 2 . Reprinted with permission from ref[80].

The empty $\pi^{*}$ orbital of NO, $\pi_{\mathrm{v}}{ }^{*}\left(\mathrm{v}=\right.$ vertical, the $\pi^{*}$ orbital orthogonal to the $\mathrm{Fe}-\mathrm{N}-\mathrm{O}$ plane $)$, forms a strong $\pi$-backbond with the $\mathrm{Fe}\left(3 \mathrm{~d}_{\mathrm{yz}}\right)$ as appears in the LUMO+2 antibonding orbital in Figure 16, right. Therefore, NO corresponds to a "classic" $\sigma$-donor/ $\pi$-acceptor ligand in ferrous heme-nitrosyls. Based on the significant donation of electron density from $\pi^{*}{ }_{h}$ of NO into $\mathrm{Fe}$ $\left(3 \mathrm{~d}_{z^{2}}\right)$, the five-coordinate complexes retain a certain degree of $\mathrm{NO}^{+}$character, reflected in the 0.53 spin density on $\mathrm{NO}$ and 0.47 on $\mathrm{Fe}$ and strong $\mathrm{Fe}-\mathrm{NO}$ bonds with a force constant $\sim 3 \mathrm{mdyn} / \AA$.

\subsubsection{Six-Coordination in NO complexes}

In turn, a six-coordinate ferric heme with NO exhibits a binding energy, $E=-3.65 \pm 0.17$ $\mathrm{kcal} / \mathrm{mol}$, strikingly lower by a factor of 6 relatively to five coordinate $\left[\mathrm{Fe}^{\mathrm{III}} \mathrm{NO}\right]^{+}$. This value is obtained from van't Hoff temperature dependent measurements while studying the equilibrium of doubly protonated microperoxydase 11 (MP11), [Fe $\left.\mathrm{Fe}^{\mathrm{III}} \mathrm{MP11} 2 \mathrm{H}\right]^{3+}$, with NO [55]. These low values are also paralleled in six-coordinate ferrous porphyrins, although in solution equilibria [9]. This striking difference in binding energy between five- and six-coordinate Fe-NO heme systems, also reflected in the equilibrium constants, has been termed by Praneeth as transaxial effect of the methylimidazole (MI) ligand and carefully described by DFT calculations involving the determination of the Fe-NO potential along the association reaction, as described in Figure 17 [59]. The reaction of model five-coordinate $\left[\mathrm{Fe}^{\mathrm{III}} \mathrm{P}-\mathrm{MI}\right]^{+}$and $\mathrm{NO}$ proceeds from the lowest energy spin state $S=2$ antiferromagnetically coupled (AFC) $S=3 / 2$ with $\mathrm{NO}(S=1 / 2)$, 
along the black line. After crossing with the $S=0$ AFC potential (red line) leading asymptotically to the low spin $\left[\mathrm{Fe}^{\mathrm{III}} \mathrm{P}-\mathrm{MI}\right]^{+}+\mathrm{NO}$, a second crossing to a $\left[\mathrm{Fe}^{\mathrm{II}} \mathrm{P}-\mathrm{MI}\right]+\mathrm{NO}^{+}$potential (blue line) is characterized. Thus, the equilibrated six coordinate $\left[\mathrm{MI}-\mathrm{Fe}^{\mathrm{III}} \mathrm{P}-\mathrm{NO}\right]^{+}$bears a partial positive charge on NO, resulting from a $\sigma$ donation from NO with a back donation to NO $\pi^{*}$ orbitals, as for the five-coordinate ferrous complex similarly described by Strickland et al. [79].

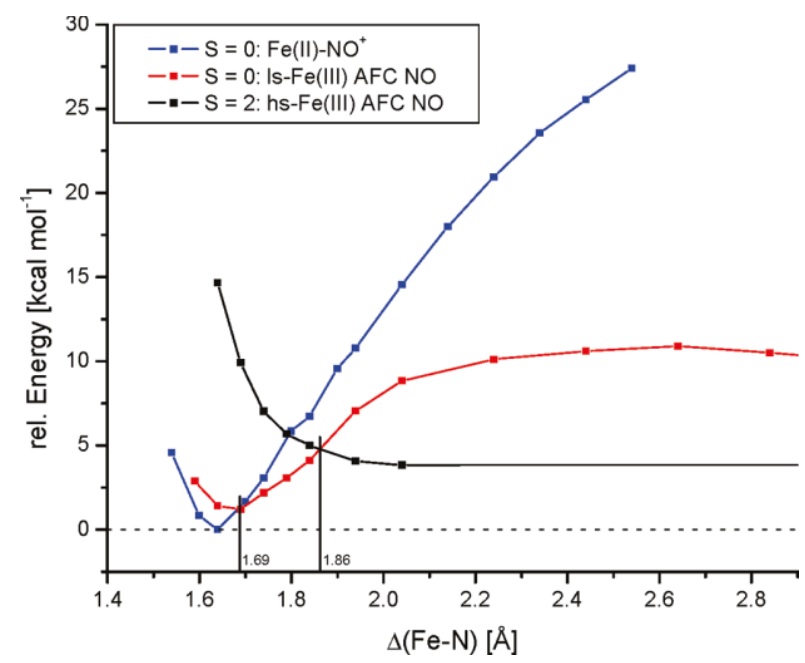

Figure 17: Calculated potential energy surfaces (PES)'s for 6C ferric heme-nitrosyls using the model system [MI-Fe $\left.{ }^{\mathrm{III}} \mathrm{P}-\mathrm{NO}\right]^{+}$. The following states are considered: (a) closed-shell [MI-Fe $\left.{ }^{\mathrm{II}}-\mathrm{NO}\right]^{+}$(blue); (b) low-spin (ls) Fe $\mathrm{IIII}^{\mathrm{II}}$ antiferromagnetically coupled (AFC) to NO (open shell $S=0$; red); (c) high-spin (hs) Fe $\mathrm{Fe}^{\mathrm{III}} \mathrm{AFC}$ coupled to $\mathrm{NO}$ ( $S=2$; black). From ref [59].

According to their calculations, the six-coordinate complex is only weakly bound, (E 5 kcal/mol), though showing all attributes of a strong bond: a short Fe-NO bond (1.6 $⿱$ A), a high Fe-N stretching force constant - twice as high in the ferrous complex (blue profile) as compared to the ferric complex (red profile) (4.82/2.26 mdyn/ $\AA$ ), supported by experimental measurements. Therefore, the properties of the energy surface of the high spin radical species $\left[\mathrm{MI}-\mathrm{Fe}^{\mathrm{III}}-\mathrm{NO}\right]^{+}$(black line in Figure 17) determine the small value of the Fe-NO bond energy in 6-coordinate ferric heme-nitrosyls and the large dissociation rate constant of NO.

Compared to experiment, it appears therefore that all ferric heme-nitrosyl complexes characterized so far fall in the regime of a $\left[\mathrm{MI}-\mathrm{Fe}^{\mathrm{II}}-\mathrm{NO}\right]^{+}$low spin ground state. This brings in the similarity in the binding of $\mathrm{Fe}^{\mathrm{III}}$ and $\mathrm{Fe}^{\mathrm{II}}$, both showing a flip to low spin with strong interaction with the $\mathrm{Fe}\left(3 \mathrm{~d}_{z^{2}}\right)$ orbital.

\subsection{The ligand affinity ladder}

While low affinity ligands reach quickly an equilibrium with iron porphyrins, many strong ligands react completely, thus precluding the determination of an equilibrium constant. This is ascribed to the very slow dissociation rate $\mathrm{k}_{\text {diss }}$ at the top of the association barrier (Scheme 1). 
In terms of the RRKM reaction rate at energy $E, k(E)=\frac{N^{\dagger}\left(E-E_{0}\right)}{h \rho(E)}$ is low from a high level density $\rho(E)$ on the ligated product side with a high well depth, with respect to the transition state level number $N^{\dagger}\left(E-E_{0}\right)$. This problem can be bypassed through the equilibrium of ligand exchange between two ligands of comparable affinities.

Ligand transfer equilibria characterized by relatively modest free energy changes are routinely accessible to FT-ICR mass spectrometry (Fourier-transform ion cyclotron resonance) and lend themselves to build a ladder of increasing affinity for ligand binding to $\mathrm{Fe}^{\mathrm{II}}$ or $\mathrm{Fe}^{\mathrm{III}}$ hemes. The goal may thus be reached for connecting the least bound and the most effective ligands. In this way, one can attain quantitative thermodynamic data for the association of NO to Fe hemes [81].

The relative Gibbs free energy for ligand transfer equilibria $\Delta G_{\mathrm{T}}{ }^{\circ}$ organized as an energy ladder of growing thermodynamic drive are shown in Figure 18 for ligand addition to [ $\left.\mathrm{Fe}^{\mathrm{III}} \mathrm{Heme}\right]^{+}$ ions. We listed ligands among substrate compounds of heme proteins or to model the various functionalities present in the protein backbone. One may note, for example, that the direct equilibrium for addition of acetone, yields the Gibbs free energy for dissociation $\Delta G_{\mathrm{D}}{ }^{\circ}=-14.6$ $\mathrm{kcal} / \mathrm{mol}$. This value, combined with $\Delta G_{\mathrm{T}}=-1.5 \mathrm{kcal} / \mathrm{mol}$ for acetone - NO ligand transfer, gives $\Delta G^{\circ}=-16.1 \mathrm{kcal} / \mathrm{mol}$ for $\mathrm{NO}$ binding to $\left[\mathrm{Fe}^{\mathrm{III}} \mathrm{Heme}\right]^{+}$ions, (Figure 18). This ladder is self consistent since the same Gibbs free energy $\Delta G^{\circ}$ value for a ligand can be obtained by different transfer routes.

\begin{tabular}{|c|c|c|c|c|c|c|}
\hline \multirow{3}{*}{$\begin{array}{l}\mathrm{CH}_{3} \mathrm{OH} \\
\mathrm{CH}_{3} \mathrm{CN} \\
\left(\mathrm{CH}_{3}\right)_{2} \mathrm{CO}\end{array}$} & 4 & & & & & \\
\hline & $\frac{\downarrow 0.6}{40.8}$ & 2.5 & & & & \\
\hline & & & $\uparrow 1.5$ & & & 2.7 \\
\hline NO & 11.4 & & & & 2.0 & \\
\hline $\mathrm{NH}_{3}$ & $\uparrow 0.5$ & & 0.8 & & $\downarrow$ & \\
\hline$\left(\mathrm{CH}_{3}\right)_{2} \mathrm{~S}$ & & 2.0 & & 2.8 & & \\
\hline THF & \pm 1.7 & & & & & \\
\hline$\left(\mathrm{CH}_{3}\right)_{2} \mathrm{NNO}$ & 3.1 & $₫ 0.5$ & & & & \\
\hline $\begin{array}{l}\mathrm{CH}_{3} \mathrm{NH}_{2} \\
\left(\mathrm{CH}_{3} \mathrm{O}\right)_{2} \mathrm{PO}(\mathrm{H})\end{array}$ & $\frac{\downarrow}{2}$ & & & & & \\
\hline $\begin{array}{l}\text { Pyridine } \\
\mathrm{CH}_{3} \mathrm{CON}\left(\mathrm{CH}_{3}\right)\end{array}$ & $\frac{\downarrow}{\downarrow} 0.7$ & $£ 1.4$ & & & & \\
\hline$\left(\mathrm{CH}_{3} \mathrm{O}\right)_{3} \mathrm{PO}$ & - & 2.0 & & & & \\
\hline
\end{tabular}

Figure 18: The $\Delta G_{D}(\mathrm{kcal} / \mathrm{mol}, 300 \mathrm{~K})$ ladder for the $\left[\mathrm{Fe}^{\mathrm{III}} \mathrm{Heme}\right]^{+}$transfer reactions between selected pairs of ligands, adapted with permission from ref [81]. 
Overall, it is found that $\Delta G^{\circ}$ values for heme cation binding display a linear relationship with the gas phase basicity for protons (GB) [81], with the most basic ligands binding [Fe $\left.{ }^{\mathrm{III}} \mathrm{Heme}\right]^{+}$ ions most tightly. Notably, NO sets apart from the correlation, behaving as an exceptional ligand for $\left[\mathrm{Fe}^{\mathrm{III}} \mathrm{Heme}\right]^{+}$despite its low GB. The remarkable kinetic and thermodynamic parameters for NO binding, shared by both four-coordinate $\mathrm{Fe}^{(\mathrm{II})}-$ and $\mathrm{Fe}^{\mathrm{III}}-$ heme ions, is consistent with the key role played by nitrosyl-heme proteins complexes in biological environments.

\section{Ferrous heme binding}

Binding of ferrous heme is a challenging process since respiration proceeds through oxygen fixation in axial position on the $\mathrm{Fe}^{\mathrm{II}}$ atom in ferrous hemoglobin. In Nature, the deoxy heme molecule is already five coordinated, and in the gas phase both four- and five-coordinate starting conditions can be selected in order to study the influence of the axial histidine in $5^{\text {th }}$ axial position. However, due to the limitation of studying ionic species, charged Fe porphyrins have been selected, such as FeTPPS (Figure 2a) [21, 23], which host at their periphery three or four negative charges depending on the Fe oxidation state, either a ferrous $\left[\mathrm{Fe}^{\mathrm{II}} \mathrm{TPPS}^{4-}\right.$ or a ferric $\left[\mathrm{Fe}^{\mathrm{III}} \mathrm{TPPS}\right]^{3-}$ complex. Previously exposed, the reactivity of ferrous heme with NO has been successfully explored using protonated substituents to derive binding properties of ferrous heme. The choice of negative ions as heme models is based on a similar cage structure as calculated or measured for heme and its models and from the same electronic distribution as determined by spin density calculations. Indeed, DFT predicts a $S=1$ triplet ground state for $\left[\mathrm{Fe}^{\mathrm{II}} \mathrm{TPPS}\right]^{4-}[21]$ as for ferrous heme [30]. The Fe-Np distance is $1.98 \AA$ [21] as for ${ }^{3}\left[\mathrm{Fe}^{\mathrm{II}} \mathrm{P}\right]$ [78]. The same comparison can be made for $\left[\mathrm{Fe}^{\mathrm{III}} \mathrm{TPPS}\right]^{3-}$ which corresponds to a ${ }^{4}\left[\mathrm{Fe}^{\mathrm{III}} \mathrm{TPPS}\right]^{3-}(S=3 / 2)$ model ferric porphyrin ground state. Complete measurements have been undertaken for the ligation of ferrous $\left[\mathrm{Fe}^{\mathrm{II}} \mathrm{TPPS}\right]^{4-}$ to obtain the binding energy with dioxygen and carbon monoxide $[21,23]$. It should be emphasized that the conditions of mono-ligation are simple to obtain by using a reduced pressure of complexing gas, since it has been observed that the second ligation was rarely favorable. So far, experiments have not reported on sixcoordination of ferrous heme with $\mathrm{O}_{2}$ or $\mathrm{CO}$ ligands. Equilibria have been observed for several ligands $\left(\mathrm{O}_{2}, \mathrm{CO}\right)$ and for $\mathrm{Fe}$ and $\mathrm{Mn}$ porphyrin complexes as $\left[\mathrm{Fe}^{\mathrm{II}} \mathrm{TPPS}\right]^{4-}+\mathrm{L} \rightleftarrows$ $\left[\mathrm{Fe}^{\mathrm{II}} \text { TPPS-L }\right]^{4-}$. Equilibrium concentrations of $\left[\mathrm{Fe}^{\mathrm{II}} \text { TPPS-L }\right]^{4-}$ and $\left[\mathrm{Fe}^{\mathrm{II}} \text { TPPS }\right]^{4-}$ ions determined by MS at fixed temperature and known ligand pressure $\mathrm{p}$ yield the equilibrium constant at $\mathrm{p}_{0}=1$ atmosphere, $K_{p}=\left[\mathrm{Fe}^{\mathrm{II}} \mathrm{TPPS}-\mathrm{L}\right]^{4-} * p_{0} /\left(\left[\mathrm{Fe}^{\mathrm{II}} \mathrm{TPPS}\right]^{4-} * p\right)$. The resulting Gibbs free 
energy $\Delta G^{\circ}=-R T \cdot \ln K_{p}$, combined with $\Delta S^{\circ}$, either calculated from the translational entropy change or by DFT yields the association enthalpies. Temperature dependent variations in the equilibrium constant yield precise values for ligand binding on $\mathrm{Fe}^{\mathrm{II}}$ or $\mathrm{Mn}^{\mathrm{II}}$ heme model porphyrin systems via the van’t Hoff equation.

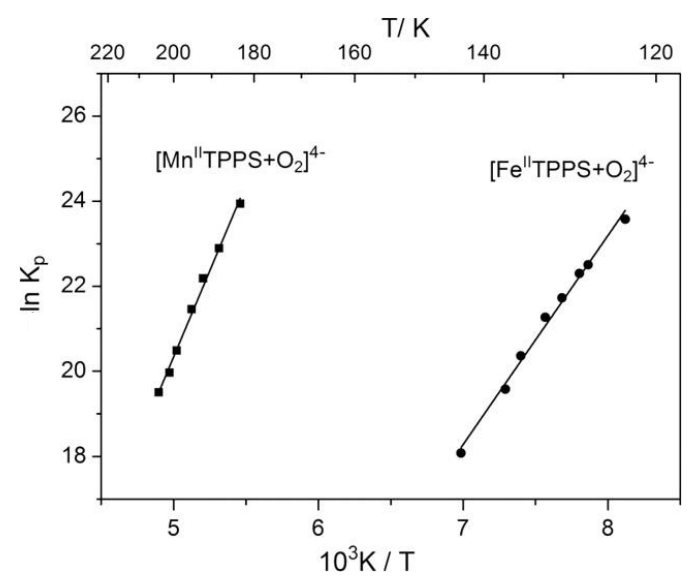

Figure 19: Van't Hoff plot of the equilibrium constants of the oxygen association/dissociation reactions and linear fits (solid lines), yielding reaction enthalpies and entropies summarized in Table 2. Reproduced from reference [21] with permission.

In the association process of $\left[\mathrm{Fe}^{\mathrm{II}} \mathrm{TPPS}\right]^{4-}$ with dioxygen, $\ln \left(K_{p}\right)$ follows a linear variation with $1 / T$, over a dynamic ratio of 150 and $40 \mathrm{~K}$ (Figure 19 ). The slopes in the $1 / T$ plot yield directly the reaction enthalpies listed in Table 2. One observes directly that Mn porphyrins bind dioxygen much more strongly than $\mathrm{Fe}$. Also, as expected, $\mathrm{CO}$ binding is $50 \%$ stronger than $\mathrm{O}_{2}$ binding as seen in Table 2 .

For both the model metal $(\mathrm{M})$ porphyrins $\left[\mathrm{M}^{\mathrm{II}} \mathrm{TPPS}\right]^{4-}$, the calculated energy values accord favorably with the experimental determinations (Table 2). For $\left[\begin{array}{ll}\mathrm{Fe}^{\mathrm{II}} & \mathrm{TPPS}-\mathrm{O}_{2}\end{array}\right]^{4-}$, $\Delta H_{r}{ }^{\text {exp }}=-9.75$ compares well to $-8.7 \mathrm{kcal} / \mathrm{mol}$ with multireference CASPT2 calculations on $\left[\mathrm{Fe}^{\mathrm{II} P}\right]$. However CASPT2 calculations do not yield the proper spin ground state, $S=1$ for Fe ${ }^{\mathrm{II}} \mathrm{P}$, as already found by Radon et al. [30], at difference with DFT calculations with most functionals. There, the $S=1 / S=2$ splitting ratio is small $1.9-4.4 \mathrm{kcal} / \mathrm{mol}$ with the B3LYP functional [30]. On the other hand, the ground state of [Fe $\left.\mathrm{P}-\mathrm{O}_{2}\right]$ has $S=1$ spin distributed as $\left[\mathrm{Fe}^{\mathrm{III}} \mathrm{P}\right]^{+}(S=1 / 2)$ and $\left[\mathrm{O}_{2}\right]^{-}(S=1 / 2)$, as determined by spin density calculations. This corresponds to the Weiss model for heme oxygen binding [82], whose direct implication is an electron donation from a low spin Fe atom to dioxygen as a result of the binding process. This electron sharing is also found in the case of six-coordinate $\left[\mathrm{MI}-\mathrm{Fe}^{\mathrm{II}} \mathrm{P}-\mathrm{O}_{2}\right]$ as described in details by Chen H. et al. [10]. 
Table 2: Reaction enthalpies obtained for the ion chemistry of metal porphyrin ions with $\mathrm{O}_{2}$ and $\mathrm{CO}$ and the calculated energies. The table includes for comparison calculated energies values for [ $\left.\mathrm{Fe}^{\mathrm{II}} \mathrm{Heme}-\mathrm{H}_{2} \mathrm{O}\right]$ systems. a) As determined for [Fe P] in ref [21], b) Values for $\Delta H$ in $\mathrm{kcal} / \mathrm{mol}$ from ref [21]. c) calculated value from ref [53]. Table adapted with permission from refs [21, 53, 54].

Spin state (total) ${ }^{\text {a) }} \quad \Delta H_{\mathrm{r}}^{\text {exp b) }} \quad \Delta E^{\text {calc b) }}$

\begin{tabular}{lcll}
\hline$\left[\mathrm{Fe}^{\mathrm{II}} \mathrm{TPPS}\right]^{4-}$ & 1 & - & \\
{$\left[\mathrm{Mn}^{\mathrm{II}} \mathrm{TPPS}\right]^{4-}$} & $3 / 2$ & - & -8.7 \\
{$\left[\mathrm{Fe}^{\mathrm{II}} \mathrm{TPPS}^{4} \mathrm{O}_{2}\right]^{4-}$} & 1 & $-9.75 \pm 0.3$ & -16 \\
{$\left[\mathrm{Mn}^{\mathrm{II}} \mathrm{TPPS}-\mathrm{O}_{2}\right]^{4-}$} & $3 / 2$ & $-16.1 \pm 0.5$ & \\
{$\left[\mathrm{Fe}^{\mathrm{II}} \text { TPPS-CO }\right]^{4-}$} & & $-15.9 \pm 0.6$ & $-6.06^{\mathrm{c}}$ \\
{$\left[\mathrm{Fe}^{\mathrm{II}} \mathrm{PP}-\mathrm{H}_{2} \mathrm{O}\right]$} & & - & $-4.68^{\mathrm{c}}$ \\
{$\left[\mathrm{Fe}^{\mathrm{II}} \mathrm{PP}-\left(\mathrm{H}_{2} \mathrm{O}\right)_{2}\right]$} & 1 & &
\end{tabular}

The landmark theoretical work of Chen H. et al. [10] is focused on the nature of the $\mathrm{Fe}^{\mathrm{II}}-$ dioxygen bond in a six-coordinate myoglobin model and under the influence of the protein reduced to the hydrogen bonding between the distal histidine and $\mathrm{O}_{2}$. The goal is to distinguish between the Pauling model of a singlet oxygen interacting with a singlet $\left[\mathrm{Fe}^{\mathrm{II}} \mathrm{P}\right]$, the Weiss model $\left[\mathrm{Fe}^{\mathrm{III+}} \mathrm{O}_{2}{ }^{-}\right]$singlet radical pair just mentioned or the McClure model with a covalent $\mathrm{Fe}^{\mathrm{II}} \mathrm{P}$ $(S=1)-\mathrm{O}_{2}(S=1)$ spin paired in $S=0$. Chen $\mathrm{H}$. et al. [10] conclude quite unambiguously that the Weiss model describes the interaction of the distal hydrogen bonded six-coordinate $\left[\mathrm{Im}-\mathrm{Fe}{ }^{\mathrm{II}} \mathrm{P}-\right.$ $\mathrm{O}_{2}$ ] complex.-The Weiss model also applies to the free complex [Im-Fe ${ }^{\mathrm{II}} \mathrm{P}-\mathrm{O}_{2}$ ], although to a lesser extent. This very detailed work inspects the lowest energy states of the [Im-Fe P-O $]-H i s$ complex using DFT/MM and CASSCF/MM multireference calculations. It endeavors to show that very similar results can be obtained with both methods, since they yield the same ground states with $S=0$ and two low lying triplet states corresponding to the antisymmetric pairing of the same orbitals for the $\mathrm{H}$ bonded complex and with similar singlet with a low triplet energy gap. Although DFT methods yield the correct spin and charge distributions, CASSCF methods allow to project the 2 reference wavefunctions onto valence bond ones describing the $\mathrm{Fe}-\mathrm{O}_{2}$ bond as show in Figure 20 by 3 functions. 


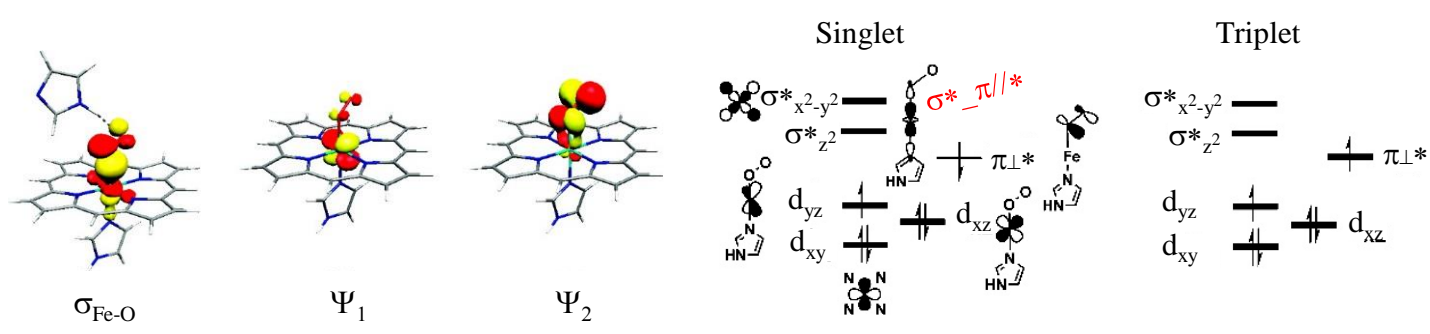

Figure 20: DFT/MM Calculations of Oxy-Mb Ferrous 6 coordinate heme bonding. Left, three orbitals responsible for Fe- $\mathrm{O}_{2}$ bonding. Right : Electronic Configurations of the Lowest Singlet and Triplet States is adapted with permission from ref [10].

The first $\sigma \mathrm{Fe}-\mathrm{O}$ bond results from the $\sigma$ type interaction between the empty $\mathrm{Fe}^{\mathrm{III}}\left(3 \mathrm{~d}_{z^{2}}\right)$ and $\pi^{/ / *}$ doubly occupied $\mathrm{O}_{2}{ }^{-}$orbital in plane with Fe-O-O, as schemed on the right hand side of Figure 20 as $\sigma_{-} \pi^{/ / *}$. The large yellow lobe on $\sigma_{\mathrm{FeO}}$ corresponds to this $\sigma$ bonding interaction along Fe-O (right in Figure 20). The other orbitals $\Psi_{1}, \Psi_{2}$ singly occupied and built from Fe $\left(3 \mathrm{~d}_{\mathrm{xz}}\right)$ and $\mathrm{O}_{2} \pi_{\mathrm{perp}} *$ contribute to the $\pi$ interaction between $\mathrm{Fe} \mathrm{d}_{\pi}$ orbital and the (perpendicular) $\mathrm{O}_{2} \pi^{*}$ antibonding orbital. This interaction is covalent and relatively weak as shows its major localization on either $\mathrm{Fe}\left(\Psi_{1}\right)$ or $\mathrm{O}_{2}\left(\Psi_{2}\right)$. In turn, what defines the nature of the bond is the composition of $\sigma_{\mathrm{FeO}}$ from the empty $\mathrm{Fe}^{+}\left(3 \mathrm{~d}_{z^{2}}\right)$ orbital with $\mathrm{O}_{2}^{-}\left(\pi^{*}\right)$. This interaction is an essentially dative bonding from $\mathrm{O}_{2}^{-}$to $\mathrm{Fe}^{+}\left(3 \mathrm{~d}_{z^{2}}\right)$; this evidence assesses the bonding mechanism to the Weiss model, but the charge on the $\mathrm{Fe}$ atom is distinct from +1 as $^{\mathrm{O}_{2}}{ }^{-}$delocalizes electron density over $d_{z^{2}}$. The $\mathrm{O}_{2}$ negative charge is 0.5 for distal histidine bound 6-coordinate Fe heme and 0.28 for the histidine free (gas phase) complex. Distal histidine is therefore polarizing the $\mathrm{O}_{2}^{-}$molecule and stabilizing the charge. Nevertheless, the bonding mechanism is still the Fe$\mathrm{O}_{2}$ initial charge transfer but to a lesser extent in the case of the gas phase complex. More recent results on 5 coordinated $\left[\mathrm{Fe}^{\Pi I} \mathrm{P}-\mathrm{O}_{2}\right]$ invoking the same process accord with the present description with the notable difference of a triplet ground state [30].

Comparison between experimental studies in the gas phase of six coordinated hemes is desirable in the gas phase especially in view of the NO complexation in 5 and 6 th coordination. Nevertheless, this electron transfer involving $\sigma$ bonding mechanism is unique to $\mathrm{O}_{2}$ complexation and distinct from that of $\mathrm{CO}$.

\section{Intermediate Fe ${ }^{I / I I I}$ heme bonding}

Protonated hemes have been used as a means to investigate ionic ferrous hemes by adding a positive charge. This additional charge is not always 'innocent' due to the possible charge 
delocalization over the $\mathrm{Fe}$ atom center, as discussed earlier. The case of $\mathrm{Fe}^{\mathrm{II}}$ protonated tetrapyridylporphyrin $\left[\mathrm{Fe}^{\mathrm{II}} \mathrm{TPy} \mathrm{PH}-\mathrm{NO}\right]^{+}$is different: there, a proton added to a basic nitrogen atom located on a peripheral pyridyl cycle remains localised. The pyridine groups located at meso positions are tilted with respect to the porphyrin plane, and thus are very poorly conjugated to it. Charge localization in an ionic $\mathrm{Fe}^{\mathrm{II}}$ porphyrin was verified in calculations on the tetra-anion $\left[\mathrm{Fe}^{\mathrm{II}} \mathrm{TPPS}\right]^{4-}$ whose spin density of unpaired electrons on $\mathrm{Fe}$ was found similar to that of the $\mathrm{Fe}^{\mathrm{II}} \mathrm{P}$ model [21]. In contrast, protonated heme formed by electrospray from the synthetic enzyme MP11 (microperoxydase 11) exhibits an intermediate situation between $\mathrm{Fe}^{\mathrm{II}}$ and $\mathrm{Fe}^{\mathrm{III}}[48]$.

Chiavarino et al.[48] calculated the spin density over the molecule and found an $\alpha$ spin increase on the iron atom (up, in blue in Figure 6) and a $\beta$ spin decrease notably at the C6 carbon. So that the former vinyl group at C6 on protoporphyrin IX has acquired a significant ethyl radical character. The situation can be described as arising from the transfer of an electron from the $\mathrm{Fe}^{\mathrm{II}}$ to the protonated porphyrin system. Integration of the spin density on the porphyrin gives a total of 0.55 electrons for the net-charge transfer from the iron to the porphyrin, which corresponds to an intermediate situation between $\left[\mathrm{Fe}^{\mathrm{II}} \mathrm{HemeH}^{+}\right]$and $\left[\mathrm{Fe}^{\mathrm{III}} \mathrm{HemeH}\right]^{+}$. Thus, the protonated ferrous heme seems to represent an interesting intermediate case between ferric and ferrous heme. This state correlates with an $S=1 \mathrm{Fe}^{\mathrm{II}}$ heme state.

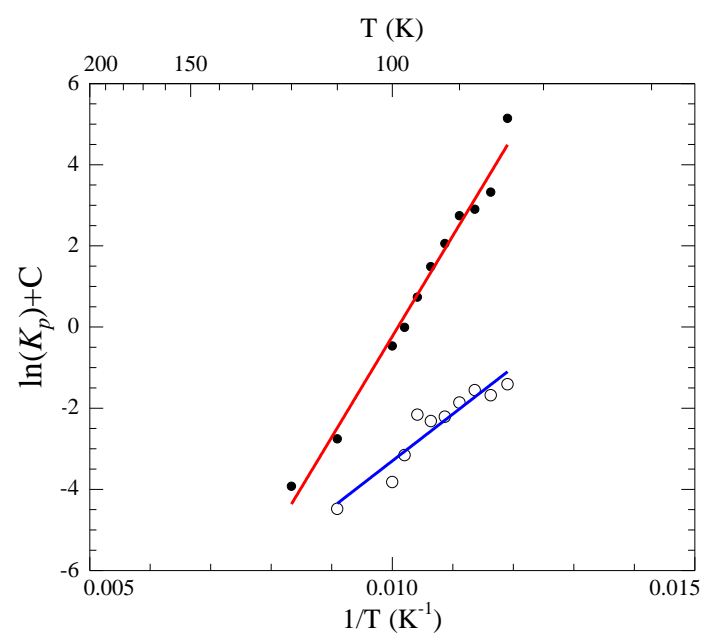

Figure 21: Van't Hoff plots of $\left(\ln \left(K_{\mathrm{p}}(\mathrm{T})\right)+\mathrm{C}\right)$ versus $1 / \mathrm{T}$ for $\left[\mathrm{Fe}^{(\mathrm{II})} \mathrm{HemeH}-\mathrm{O}_{2}\right]^{+}$( full circles and linear fit in red) and [Fe $\mathrm{Fe}^{\mathrm{III}}$ heme- $\left.\mathrm{O}_{2}\right]^{+}$(open circles and linear fit in blue) obtained simultaneously in the same experiment. $\ln \left(K_{p}(\mathrm{~T})^{*} P_{O_{2}}\right)$ is the ratio of of complexed [ $\left.\mathrm{Fe}^{(\mathrm{II})} \mathrm{HemeH}-\mathrm{O}_{2}\right]^{+}$to uncomplexed [ $\left.\mathrm{Fe}^{(\mathrm{II})} \mathrm{HemeH}\right]^{+}$and $\mathrm{C}=\ln \left(P_{\mathrm{O}_{2}}\right)$. Reproduced from ref [53] with permission.

The van't Hoff measurements (Figure 21, red line) for the complexation of $\mathrm{O}_{2}$ on this system reveal a binding energy $E_{\mathrm{FeHemH}+}=-4.4 \pm 0.4 \mathrm{kcal} / \mathrm{mol}$, twice the $E_{\mathrm{FeHem}+}$ value for ferric 
heme, $-2.26 \mathrm{kcal} / \mathrm{mol}$ (Figure 21, blue line). The binding energy $E_{\mathrm{FeHemH}}$ is also 2.1 times smaller than that of $\left[\mathrm{Fe}^{\mathrm{II}} \mathrm{TPPS}\right]^{4-}$ with $\mathrm{O}_{2}(8.7 \mathrm{kcal}$ Table 2$)$.

At variance, a similar NO binding with four-coordinate hemes (ferrous and ferric) is observed for protonated heme $\left[\mathrm{Fe}^{(\mathrm{II})} \mathrm{HemeH}^{+}\right]$, as shown experimentally and reported [81] in Table 1. One should consider that the geometrical structure of four-coordinate $\left[\mathrm{Fe}^{(\mathrm{II})} \mathrm{HemeH}^{+}\right]$resembles that of $\left[\mathrm{Fe}^{\mathrm{II}} \mathrm{Heme}\right]$ with a bent $\mathrm{Fe}-\mathrm{N}-\mathrm{O}$ structure $\left(145.6^{\circ} 149.2^{\circ}\right)$ and an $\mathrm{Fe}-\mathrm{O}$ distance respectively of 1.71 and $1.717 \AA$ [27], in difference to the linear [Fe $\left.\mathrm{Fe}^{\mathrm{III}} \mathrm{Heme}-\mathrm{NO}\right]^{+}$complex. The reaction with NO, a strong field ligand, yields low spin, singlet and doublet, nitrosyl complexes from $\left[\mathrm{Fe}^{\mathrm{III}} \mathrm{Heme}\right]^{+}$or $\left[\mathrm{Fe}^{(\mathrm{II})} \mathrm{HemeH}\right]^{+}$ions, respectively. A binding energy of $34.4 \mathrm{kcal} / \mathrm{mol}$ is calculated for $\left[\mathrm{Fe}^{\mathrm{III}} \mathrm{Heme-NO}\right]^{+}$with respect to quartet $\left[\mathrm{Fe}^{\mathrm{III}} \mathrm{Heme}\right]^{+}$and doublet NO, while a value of $33.5 \mathrm{kcal} / \mathrm{mol}$ is predicted for $\left[\mathrm{Fe}^{(\mathrm{II})} \mathrm{HemeH}-\mathrm{NO}\right]^{+}$relative to the dissociation into triplet $\left[\mathrm{Fe}^{(\mathrm{II})}-\mathrm{HemeH}\right]^{+}$and ${ }^{2} \mathrm{NO}$ [22], as shown in Table 3. These values indicate a quite comparable binding energy for $\mathrm{NO}$ addition to either $\left[\mathrm{Fe}^{\mathrm{III}} \mathrm{Heme}^{+}\right.$or $\left[\mathrm{Fe}\left({ }^{\mathrm{II}}\right)_{-}\right.$ $\mathrm{HemeH}]^{+}$ions, and fully agree with the experimental findings regarding the NO association equilibria of naked iron(II)- and iron(III)-heme ions.

The protonated complex of iron protoporphyrin ligated to $\mathrm{H}_{2} \mathrm{O}$ was also observed $\left[\mathrm{Fe}^{(\mathrm{II})} \mathrm{HemeH}\left(\mathrm{H}_{2} \mathrm{O}\right)\right]^{+}[54]$. The signal was too weak to determine its precise binding energy, a limiting value $\mathrm{E}>-3.1 \mathrm{kcal} / \mathrm{mol}$ was however derived.

Table 3 Observed and calculated binding energy of $\mathrm{O}_{2}, \mathrm{NO}, \mathrm{H}_{2} \mathrm{O}$ with protonated heme: Table adapted with permission from refs $[53,54]$.

\begin{tabular}{lll}
\hline & $\Delta E_{\text {Exp }}$ & $\Delta E_{\text {calc }}$ \\
\hline$\left[\mathrm{Fe}^{(\mathrm{II})} \mathrm{HemeH}-\mathrm{O}_{2}\right]^{+}$ & -4.4 & \\
{$\left[\mathrm{Fe}^{(\mathrm{II})} \mathrm{HemeH}-\mathrm{NO}\right]+$} & & -33.5 \\
{$\left[\mathrm{Fe}^{(\mathrm{II})} \mathrm{HemeH}-\mathrm{H}_{2} \mathrm{O}\right]^{+}$} & Weakly formed & -9.6 \\
{$\left[\mathrm{Fe}^{(\mathrm{II})} \mathrm{HemeH}-\left(\mathrm{H}_{2} \mathrm{O}\right)_{2}\right]^{+}$} & Not observed & -6.01 \\
\hline
\end{tabular}

\section{Ferric Heme Bonding}

Ferric heme bonding is significantly different from that of ferrous heme and its binding can be uniquely measured in the gas phase because of competing ligation reactions in the condensed phase. 


\subsection{Weak Ferric Heme Ligation $\left(\mathrm{CO}, \mathrm{O}_{2}\right)$}

The gas phase binding of heme ions has been measured via temperature variations of the equilibrium constant for the ligation of $\mathrm{L}$ to heme ions, $K p$, via the ratio of ligated to unligated heme adducts. Van't Hoff plots are represented for the ligation of $\mathrm{CO}$ (a) and $\mathrm{O}_{2}$ (b) to $\left[\mathrm{Fe}^{\mathrm{III}} \mathrm{Heme}\right]^{+}$at the same partial pressure (Figure 22). The resulting semi-logarithmic plots of $\ln \left([\right.$ ligated $\left.] /[\text { unligated }]^{+}\right)$as a function of $1 / T$ are linear in different temperature ranges over a dynamical range of 50 . The ligand affinity can be characterized at a pressure $p_{\mathrm{L}}$ of the ligand by the temperature $T_{1}$ of equal concentration of ligated and free complex $1=$ $I_{\left[\mathrm{Fe}^{\mathrm{III}} \mathrm{Heme}-\mathrm{L}\right]^{+}} / I_{\left[\mathrm{Fe}^{\mathrm{III}} \mathrm{Heme}\right]^{+}}=K_{P}\left(T_{1}\right) \cdot p_{\mathrm{L}}$. It is indicated by a dotted line in Figure 22a. Carbon monoxide binds ferric heme twice as strongly $(E=-4.63 \pm 0.43 \mathrm{kcal} / \mathrm{mol})$ as dioxygen $(E=-2.26 \pm$ $0.26 \mathrm{kcal} / \mathrm{mol})$, which is also manifest in $T_{1}(\mathrm{CO})=130 \mathrm{~K}$ compared to $T_{1}\left(\mathrm{O}_{2}\right)=78 \mathrm{~K}$. These two
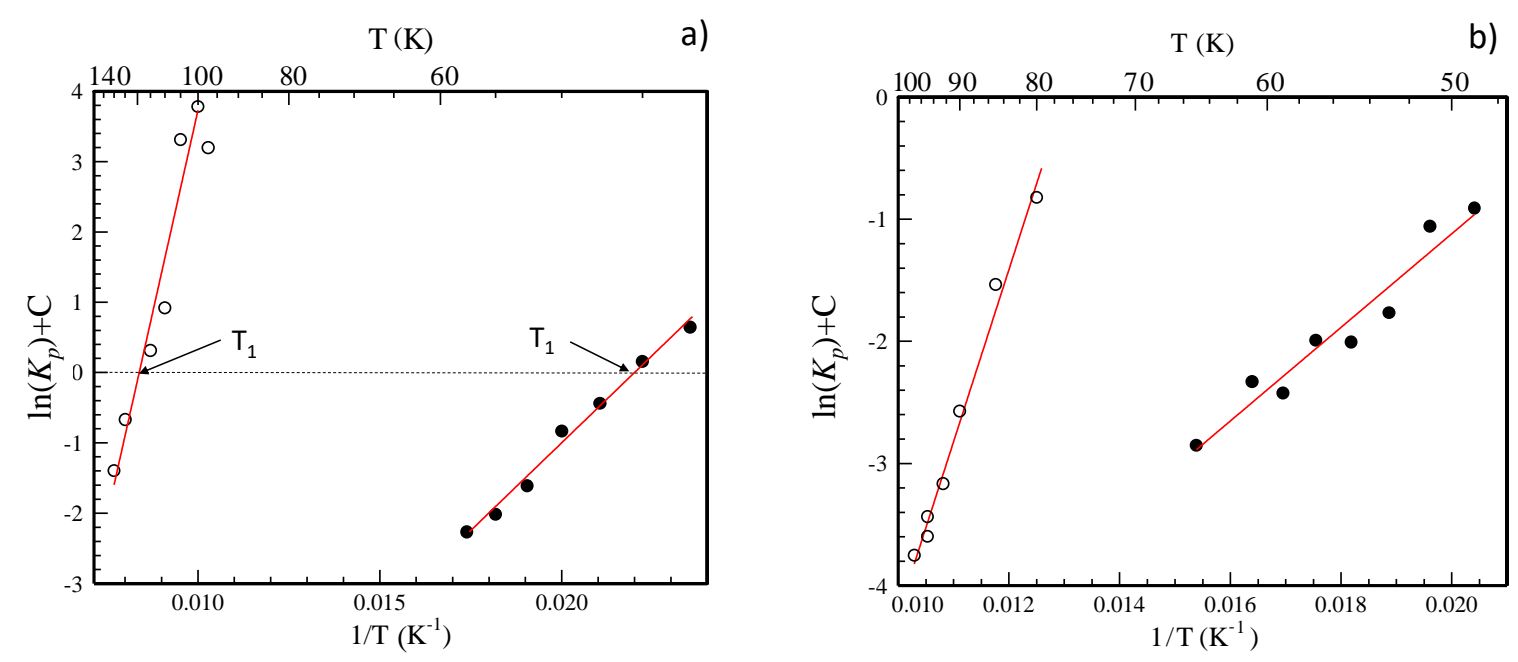

Figure 22: van't Hoff diagrams for the equilibrium between:

a) $\left[\mathrm{Fe}^{\mathrm{III}} \mathrm{Heme}-\mathrm{CO}\right]^{+}$and $\mathrm{CO}+\left[\mathrm{Fe}^{\mathrm{III}} \mathrm{Heme}\right]^{+}(5 \mathrm{C}$ bond $)$, empty circles; $\left[\mathrm{MI}-\mathrm{Fe}^{\mathrm{III}} \mathrm{Heme}-\mathrm{CO}\right]^{+}$and $\mathrm{CO}+\left[\mathrm{Fe}{ }^{\mathrm{III}} \mathrm{Heme}-\mathrm{MI}\right]^{+}(6 \mathrm{C}$ bond), filled circles. The dotted horizontal line corresponds to the equal concentrations of ligated and free [Fe $\mathrm{Fe}^{\mathrm{III}} \mathrm{Heme}^{+}$

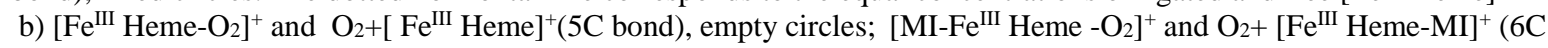
bond), filled circles.

Bottom axis: inverse temperatures, Kelvin ${ }^{-1}$; top axis Kelvin; left axis natural logarithm of the equilibrium constant $+\mathrm{C}$, $\left(\mathrm{C}=\ln \left(p_{\mathrm{L}}\right)\right) ; p_{\mathrm{L}}$ is the ligand partial pressure (see text). With permission of ref [55].

binding energies, although small in comparison to ferrous heme (smaller by a factor of 3 for $\mathrm{CO}$ and 4.3 for $\mathrm{O}_{2}$, see Table 2), represent an important axial ligation, much stronger than that of $\mathrm{N}_{2}(0.54 \mathrm{kcal} / \mathrm{mol}$ [17]), which is bound by charge dipole interactions.

As we already noted for $\mathrm{Fe}^{\mathrm{III}}$-NO binding, the addition of a six coordinating ligand diminishes further the binding to ferric heme. In Figure 22-a, it appears that equal concentrations for sixcoordinate $\left[\mathrm{MI}-\mathrm{Fe}^{\mathrm{III}} \mathrm{Heme}-\mathrm{CO}\right]^{+}$and $\left[\mathrm{MI}-\mathrm{Fe}^{\mathrm{III}} \mathrm{Heme}-\mathrm{O}_{2}\right]^{+}$were obtained at a much lower 
temperature, $T_{1}=47 \mathrm{~K}$ than in five coordinate $\left(\mathrm{T}_{1}=120 \mathrm{~K}\right)$. Indeed, at $120 \mathrm{~K}\left(T_{1}\right.$ in fivecoordinate heme, 5C), the ratio of ligation of $\mathrm{CO}$ in $6 \mathrm{C}$ only amounts to $2.510^{-3}$. The temperatures of equal concentration $T_{1}$ are thus a very sensitive means of scaling the relative affinities of ligands in $5 \mathrm{C}$ and $6 \mathrm{C}$. Comparing $6 \mathrm{C}$ and $5 \mathrm{C}$ coordination of $\mathrm{O}_{2}$ leads to the same results as for $\mathrm{CO}$ with a reduction of the binding energy by a factor of $\approx 3$, as reported in Table 4. Table 4 summarizes the experimental binding energies of different ligands $\left(\mathrm{O}_{2}, \mathrm{CO}, \mathrm{NO}\right)$ with $5 \mathrm{C}$ and $6 \mathrm{C}$ ferric heme and a comparison between the effects of two $\sigma$ donors $\mathrm{MI}$ and histidine in $[\mathrm{MP} 112 \mathrm{H}]^{3+}$ in 5 th axial coordination.

The $\sigma$-donor effect is not specific to this compound $\mathrm{N}$-methyl imidazole, and was observed in the ligation of the doubly protonated microperoxydase, $[\mathrm{MP} 11+2 \mathrm{H}]^{3+}$ (schemed in ref [55]) with $\mathrm{O}_{2}, \mathrm{CO}$ and $\mathrm{NO}$ in $6 \mathrm{C}$. The binding energy derived from the van't Hoff measurements and temperature corrections indicates a similar effect in the ratio of binding energies: $E=-0.69$ $\pm 0.14 \mathrm{kcal} / \mathrm{mol}\left(\left[\mathrm{MP} 112 \mathrm{H}-\mathrm{O}_{2}\right]^{3+}\right)$ as compared to the five coordinate heme value $E=-2.26 \pm$ $0.26 \mathrm{kcal} / \mathrm{mol}\left(\left[\mathrm{Fe}^{\mathrm{III}} \mathrm{Heme}-\mathrm{O}_{2}\right]^{+}\right.$) (see Table 4). NO was coordinated to $[\mathrm{MP} 11+2 \mathrm{H}]^{3+}$ with a histidine ligand in fifth axial position. A small value for the ligation energy was found as $3.65 \pm 0.17 \mathrm{kcal} / \mathrm{mol}$, which represents a smaller value by a factor of $\approx 7$ with respect to the five coordinate species observed in an ICR trap at room temperature [22] , [16].

Also, as we shall discuss further, the binding of $\mathrm{O}_{2}$ and $\mathrm{CO}$ to ferric heme does not involve a spin flip, as it does in hemoproteins in ferrous hemes for CO in fifth [21] and sixth coordination or for $\mathrm{O}_{2}$ in sixth coordination.

\subsection{Strong Ligands in Ferric Heme Ligation $\left(\mathrm{H}_{2} \mathrm{O}, \mathrm{NO}, \mathrm{MI}\right)$}

At variance with the previous small molecules, the affinity of ligands $\mathrm{L}=\mathrm{H}_{2} \mathrm{O}$, NO, MI does not decrease in ferric heme compared to ferrous heme. As reported above, NO is strongly bound in fifth coordination to both $\left[\mathrm{Fe}^{\mathrm{III}} \mathrm{Heme}\right]^{+}$and $\left[\mathrm{Fe}^{(\mathrm{II})} \mathrm{HemeH}\right]^{+}$. Imidazole molecules, as strong $\sigma$-donors via the nitrogen free electron pairs, interact strongly with ferric heme [55] with a calculated (B3LYP/TZP) binding energy of $-25.17 \mathrm{kcal} / \mathrm{mol}$. This value is important and far greater than that calculated (PBEO/TZP) for the ferrous porphyrin complex [Fe $\left.{ }^{\mathrm{II}} \mathrm{P}-\mathrm{Im}\right]$ $15 \mathrm{kcal} / \mathrm{mol}$, or $-3 \mathrm{kcal} / \mathrm{mol}$ (B3LYP/TZP) [45].

Water binding to ferric heme amounts to $-12.2 \pm 0.6 \mathrm{kcal} / \mathrm{mol}[54]$ as measured by its van't Hoff equilibrium dependence. Binding to $\mathrm{H}_{2} \mathrm{O}$ is more favourable for ferric than for ferrous hemoproteins. Indeed cytochrome $\mathrm{P} 450$ ( $\left.\mathrm{Fe}^{\mathrm{III}}\right)$ binds $\mathrm{H}_{2} \mathrm{O}$, while myoglobin $\left(\mathrm{Fe}^{\mathrm{II}}\right)$ does not at room temperature. On the other hand, gas phase experiments show that protonated heme, 
intermediate between $\mathrm{Fe}^{\mathrm{II}}$ and $\mathrm{Fe}^{\mathrm{III}}$ heme, binds $\mathrm{H}_{2} \mathrm{O}$ with an energy lower than $-7 \mathrm{kcal} / \mathrm{mol}$ [54], suggesting that ferric heme is a stronger binder to water than ferrous heme.

As for the $\mathrm{CO}$ and $\mathrm{O}_{2}$ ligands, the action spectrum of $\left[\mathrm{Fe}^{\mathrm{III}} \mathrm{Heme}-\mathrm{H}_{2} \mathrm{O}\right]^{+}$shown in Figure 23 reveals no change in spin state through binding, since it is very similar to that of $\left[\mathrm{Fe}^{\mathrm{III}} \mathrm{Heme-}\right.$ $\left.\mathrm{N}_{2}\right]^{+}$presented in Figure 8 and typical of an intermediate spin state $S=3 / 2$. The spectrum of the water complex is well described by the same calculations involving the intermediate spin water complex as the nitrogen complex, with the $\mathrm{Q}$ band region at $500 \mathrm{~nm}$ and the charge transfer at $617 \mathrm{~nm}$.

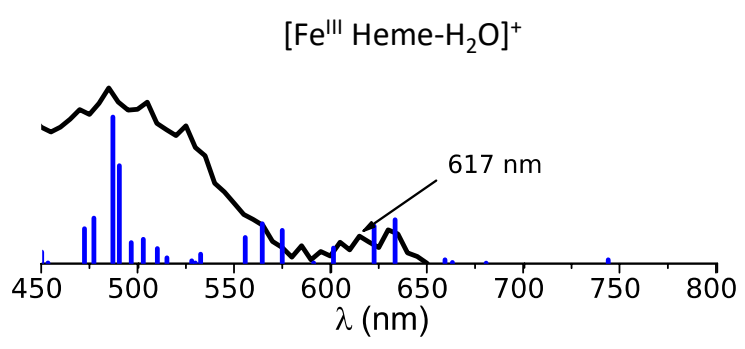

Figure 23: Action spectrum of the $\left[\mathrm{Fe}{ }^{\mathrm{III}} \mathrm{Heme}-\mathrm{H}_{2} \mathrm{O}\right]^{+}$complex observed by $\left[\mathrm{Fe}^{\mathrm{III}} \mathrm{Heme}\right]^{+}$detection, obtained at $\mathrm{T}_{\text {Trap }}=155 \mathrm{~K}$ (black). Calculated absorption spectrum, blue (see text). Reproduced with permission from ref [54].

As one out of six ligands of $\mathrm{Fe}^{\mathrm{III}}$, water binds with less affinity to ferric heme. This is found in the case of bis-ligated water with a diminished energy for the second ligation, $-9 \pm 0.9 \mathrm{kcal} / \mathrm{mol}$ compared to the first, $-12.2 \pm 0.6$. The six-coordinate complex, $\left[\mathrm{MI}-\mathrm{Fe}^{\mathrm{III}} \mathrm{Heme}-\mathrm{H}_{2} \mathrm{O}\right]^{+}$, presents a binding energy in the gas phase $\sim 7 \mathrm{kcal} / \mathrm{mol}$.

The geometrical structure of the ferric heme water complex has been calculated using DFT (Figure 24) and is in reasonable agreement with diffraction measurements[83]. The structure shows an $\mathrm{HOH}$ molecule parallel to the porphyrin plane and one $\mathrm{H}$ atom directed towards the carboxyl groups. This parallel configuration is a strong indication of the interaction of the $3 \mathrm{a}_{1}$ (vertical) orbital of $\mathrm{H}_{2} \mathrm{O}$ as a $\sigma$ donor with $\mathrm{Fe}\left(3 \mathrm{~d}_{z^{2}}\right)$ [79].

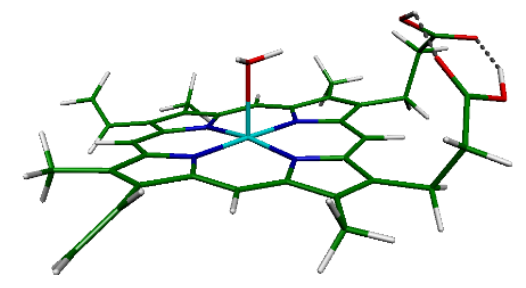

Figure 24: Structure of the ferric heme water complex, Fe-O distance $2.28 \AA$ A. Reproduced with permission from ref [54]. 
The binding energy of water with $\left[\mathrm{Fe}^{\mathrm{III}} \mathrm{Heme}\right]^{+}, \mathrm{E}=-12.2 \pm 0.6 \mathrm{kcal} / \mathrm{mol}$, is in excellent agreement with the calculated value by DFT, E=-11.7 kcal $/ \mathrm{mol}$. The calculations also indicate a decrease of the energy in the second $\mathrm{H}_{2} \mathrm{O}$ axial bond with ferric heme, with an experimental value of -7.14 to be compared with $-9 \pm 0.9 \mathrm{kcal} / \mathrm{mol}$. This drop in the second axial bond energy is interpreted as a competition for $\sigma$ donation in the $\mathrm{Fe}\left(3 \mathrm{~d}_{z^{2}}\right)$ orbital.

There are no experimental data on $\mathrm{H}_{2} \mathrm{O}$ binding to five-coordinate ferrous heme to compare with the above ferric ones. For six-coordinate $\left[\mathrm{MI}-\mathrm{Fe}^{\mathrm{II}} \mathrm{P}-\mathrm{H}_{2} \mathrm{O}\right]$ theory predicts a $S=0$ spin state through a crossing from the initial $S=2$ spin state for $\left[\mathrm{Fe}^{\mathrm{II}} \mathrm{P}-\mathrm{MI}\right]$ and a $-12.7 \mathrm{kcal} / \mathrm{mol}$ binding at the B3LYP level [79]. At the same B3LYP level of calculations, a higher value is obtained for [MI-Fe $\left.{ }^{\mathrm{II}} \mathrm{P}-\mathrm{CO}\right],-15 \mathrm{kcal} / \mathrm{mol}$, in agreement with the observation of strong affinity of $\mathrm{CO}$ to myoglobin in presence of water. This global binding value for $\left[\mathrm{MI}-\mathrm{Fe}^{\mathrm{II}} \mathrm{P}-\mathrm{H}_{2} \mathrm{O}\right]$ is similar to that obtained for ferric heme, but is obtained through a spin flip to $S=0$.

\subsection{Calculation results on the ligation of Ferric Heme}

A wealth of informations on free and ligated ferric porphyrins and hemes can be obtained from DFT calculations such as their structures and ground state energies. One essential information is that all ligands bind in axial ligation even the weakest coordinating ligand, $\mathrm{N}_{2}$.

The splitting of the spin levels from their ground states for various systems in $4^{\text {th }}, 5^{\text {th }}$ and $6^{\text {th }}$ coordination are represented in Figure $7 \mathrm{~b}$. It is seen that apart from cases such as $\left[\mathrm{Fe}^{\mathrm{III}} \mathrm{P}-\mathrm{Im}\right]^{+}$, the spin splitting does not change much after complexation. In other words, what characterizes the binding of ferric hemes is the absence of spin crossing with the exception of NO. Then, the observed calculated binding energies referred to each spin state are similar and do not show any preference to low spin states like for ferrous hemes, as shown in Figure $7 \mathrm{a}$ and Table 4. However, other calculations have indicated a spin flip for $\left[\mathrm{Fe}^{\mathrm{III}} \mathrm{P}-\mathrm{CO}\right]^{+}$to low spin $S=1 / 2$ with larger total energies and a large bonding with respect to $\left[\mathrm{Fe}^{\mathrm{III}} \mathrm{P}\right]^{+}(\mathrm{S}=1 / 2)$. This result is contradicted by experiments (infrared [25], visible [55]), and would require a large saddling deformation of the heme porphyrin structures, to yield a binding energy $E_{\mathrm{B}}=-10 \mathrm{kcal} / \mathrm{mol}$ compared to $-5.94 \mathrm{kcal} / \mathrm{mol}$ without spin flip. Since such deformation is unrealistic and not observed, it is therefore maintained that flipping from high $(5 / 2)$ or medium spin $(3 / 2)$ to low spin $(1 / 2)$ is exceptional in the course of ligation to ferric heme. As a low spin ferric heme would deplete the $\mathrm{Fe}\left(3 \mathrm{~d}_{z^{2}}\right)$ orbitals, the $\sigma$ donation to half-filled $3 \mathrm{~d}_{z^{2}}$ is inefficient for $\left[\mathrm{Fe}^{\mathrm{III}} \mathrm{Heme}\right]^{+}$, which can be viewed as inducing 3 electron bonds, usually much lower in energy than 2 electron bonds. Typically, in the case of $\left[\mathrm{Fe}^{\mathrm{III}} \mathrm{Heme}-\mathrm{H}_{2} \mathrm{O}\right]^{+}$, the calculated contribution 
of the dispersion to the binding amounts to a high proportion in the total bond energy $-11.68 \mathrm{kcal} / \mathrm{mol}$ with -9.21 for dispersion [54] (Table 5).

From calculations, the combination of spins between the Fe atom spin and that of the ligand depends on the strength of the bond: for the two ligands examined NO $(S=1 / 2)$ and $\mathrm{O}_{2}(S=1)$ the situation is opposite. NO combines in $S=0[\mathrm{Fe} \mathrm{P-NO}]^{+}$and $\mathrm{O}_{2}$ complexes with parallel spins in $S=5 / 2\left[\mathrm{Fe} \mathrm{P}-\mathrm{O}_{2}\right]^{+}$.

Table 4: Binding energies of penta- and hexa-coordinated ferric $\left[\mathrm{Fe}^{\mathrm{III}} \mathrm{P}\right]^{+}$.

Notes: a ) Experimental values obtained from refs [17, 55], b) Experimental value from ref [16] and [22], c) The calculated value has been obtained for model $\mathrm{Fe}^{\mathrm{III}}$ porphyrin without substituents, d) the binding energy from ref [55] is corrected by the BSSE value, e) The theoretical value for the binding energy of $\mathrm{NO}$ to [MI-Fe $\left.{ }^{\mathrm{III}} \mathrm{P}\right]^{+}$system is the same as in ref [59], determined at the B3LYP/TZVP level of theory, f) ref [84], g) ref [22]. Table adapted with permission from refs [17, 55, 59].

\section{Experiment $^{\text {a) }} \quad B 3 L Y P / L a N 2 d Z^{c)} \quad B 3 L Y P / \operatorname{def2-TZVP}{ }^{c, d)}$}

\begin{tabular}{|c|c|c|c|c|}
\hline Complex & $\begin{array}{l}\text { Spin } \\
\text { State } \\
\text { (total) }\end{array}$ & $\begin{array}{c}E \\
\text { (kcal/mol) }\end{array}$ & $\begin{array}{c}E_{\mathrm{b}} \\
(\mathrm{kcal} / \mathrm{mol})\end{array}$ & $\begin{array}{c}E_{\mathrm{b}} \\
(\mathrm{kcal} / \mathrm{mol})\end{array}$ \\
\hline$\left[\mathrm{Fe}^{\mathrm{III}} \text { Heme-MI }\right]^{+}$ & $5 / 2$ & $>-51$ & & -25.17 \\
\hline 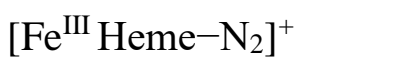 & $3 / 2$ & $-0.54 \pm 0.11$ & & \\
\hline$\left[\mathrm{Fe}^{\mathrm{III}} \text { Heme- }-\mathrm{O}_{2}\right]^{+}$ & $5 / 2$ & $-2.26 \pm 0.26$ & $-6.83^{f)}$ & $\sim 0$ \\
\hline$\left[\mathrm{MI}-\mathrm{Fe}^{\mathrm{III}} \text { Heme }-\mathrm{O}_{2}\right]^{+}$ & & $-0.60 \pm 0.14$ & & \\
\hline$\left[\begin{array}{lll}\mathrm{MP} 11 & 2 \mathrm{H} & -\mathrm{O}_{2}\end{array}\right]^{3+}$ & & $-0.69 \pm 0.14$ & & \\
\hline$\left[\mathrm{Fe}^{\mathrm{III}} \mathrm{Heme}^{-\mathrm{CO}]^{+}}\right.$ & $3 / 2$ & $-4.63 \pm 043$ & & -5.94 \\
\hline$\left[\mathrm{MI}-\mathrm{Fe}^{\mathrm{III}} \mathrm{Heme}^{-\mathrm{CO}]^{+}}\right.$ & $5 / 2$ & $-0.86 \pm 014$ & & +0.21 \\
\hline$\left[\mathrm{Fe}^{\mathrm{III}} \text { Heme-NO }\right]^{+}$ & 0 & $-24.88 \pm 0.71^{b)}$ & & $-34.4^{\mathrm{g})}$ \\
\hline$[\mathrm{MP} 11 \text { 2H-NO }]^{3+}$ & 0 & $-3.65 \pm 0.17$ & & $-3.9^{\mathrm{e})}$ \\
\hline
\end{tabular}

While in present ferric heme calculations dioxygen is not found to bind ferric heme, CO binds weakly in 5th coordination and $\mathrm{H}_{2} \mathrm{O}$ more strongly in full accord with experimental values, seeTable 4 . Also, the effect of the sixth coordination with a strong $\sigma$ donor (MI) in $5^{\text {th }}$ position 
is striking: in all cases, bonding is strongly reduced with $\left[\mathrm{MI}-\mathrm{Fe}{ }^{\mathrm{III}} \mathrm{P}-\mathrm{CO}\right]^{+}$as the most notable example. This effect has been termed as a trans-axial-effect resulting from a competition between the $\sigma$ donations from MI or the other axial ligand to the $\mathrm{Fe}\left(3 \mathrm{~d}_{z^{2}}\right)$ orbital.

Table 5: Details of the experimental and calculated electronic binding energies, respectively $\Delta E, \Delta E \mathrm{c}$ (in $\mathrm{kcal} / \mathrm{mol}$ ) for the reaction of $\mathrm{X}$ $+\mathrm{H}_{2} \mathrm{O} \rightarrow\left[\mathrm{X}-\mathrm{H}_{2} \mathrm{O}\right]\left(\mathrm{X}=\left[\mathrm{Fe}^{\mathrm{III}} \mathrm{Heme}^{+}\right.\right.$, $\left[\mathrm{Fe}^{\mathrm{III}} \mathrm{Heme}-\mathrm{MI}\right]^{+},\left[\mathrm{Fe}^{\mathrm{III}} \mathrm{Heme}-\mathrm{H}_{2} \mathrm{O}\right]^{+}$and $\left.\left[\mathrm{Fe}^{(\mathrm{II})} \mathrm{HemeH}^{+}\right]\right)$, in various ligation condition 5coordinate and 6-coordinate (see text). The theoretical value has been calculated using single point OPTX-PBE/cc-pVTZ (aug-cc-pVTZ for $\mathrm{Fe}, \mathrm{O}$ and $\mathrm{N}$ ) calculations are made on previously optimized structures at the OPTX-PBE/DZVP-GGA level.

a) $\Delta E_{c}$ stands for the corrected binding energy with ZPE, dispersion and BSSE (see text).

b) These complexes are weakly observed, their binding energy $(\Delta E) \sim-7 \mathrm{kcal} / \mathrm{mol}$, see text.

c) six coordinated heme with either $\mathrm{H}_{2} \mathrm{O}$ or MI ligands on each porphyrin face. Table adapted with permission from ref [54].

\begin{tabular}{|c|c|c|c|c|c|c|c|}
\hline \multirow{2}{*}{ Complex } & \multirow{2}{*}{$\begin{array}{l}\text { Spin } \\
\text { state }\end{array}$} & \multirow{2}{*}{$\begin{array}{c}\text { Experiment } \\
\Delta E\end{array}$} & \multicolumn{5}{|c|}{ Theory } \\
\hline & & & $\Delta \varepsilon$ & $\mathrm{ZPE}$ & BSSE & dispersion & $\Delta E_{\mathrm{c}}{ }^{\mathrm{a}}$ \\
\hline$\left[\mathrm{Fe}^{\mathrm{III}} \mathrm{Heme}-\mathrm{H}_{2} \mathrm{O}\right]^{+}$ & $3 / 2$ & $-12.2 \pm 0.6$ & -5.73 & 2.63 & 0.63 & -9.21 & -11.68 \\
\hline$\left[\mathrm{Fe}^{(\mathrm{II})} \mathrm{HemeH}-\mathrm{H}_{2} \mathrm{O}\right]^{+}$ & 1 & $\begin{array}{l}\text { Weakly } \\
\text { formed } \\
>-3.1\end{array}$ & -3.39 & 2.33 & 0.61 & -9.17 & -9.62 \\
\hline$\left[\mathrm{Fe}^{\mathrm{II}}\right.$ Heme- $\left.\mathrm{H}_{2} \mathrm{O}\right]$ & 1 & - & 0.65 & 1.96 & 0.60 & -9.27 & -6.06 \\
\hline$\left[\mathrm{Fe}^{\mathrm{III}} \text { Heme- }-\left(\mathrm{H}_{2} \mathrm{O}\right)_{2}\right]^{+\mathrm{c}}$ & $3 / 2$ & $-9 \pm 0.9$ & -1.22 & 2.16 & 0.59 & -8.67 & -7.14 \\
\hline$\left[\mathrm{Fe}^{(\mathrm{II})} \mathrm{HemeH}-\left(\mathrm{H}_{2} \mathrm{O}\right)_{2}\right]^{+\mathrm{c}}$ & 1 & $\begin{array}{c}\text { Not } \\
\text { observed }\end{array}$ & -0.25 & 1.98 & 0.58 & -8.32 & -6.01 \\
\hline$\left[\mathrm{Fe}^{\mathrm{II}} \text { Heme- }\left(\mathrm{H}_{2} \mathrm{O}\right)_{2}\right]^{\mathrm{c}}$ & 1 & - & 1.48 & 1.67 & 0.53 & -8.36 & -4.68 \\
\hline$\left[\mathrm{MI}-\mathrm{Fe}^{\mathrm{III}} \mathrm{Heme}-\mathrm{H}_{2} \mathrm{O}\right]^{+\mathrm{c}}$ & $5 / 2$ & $\sim-7^{b}$ & 1.99 & 2.23 & 0.61 & -12.27 & -7.44 \\
\hline
\end{tabular}

\section{Calculated charge distributions in ferrous and ferric hemes}

Natural Populations Analyses [85] and iterative Hirshfeld [86] partial charges (Table 6) are descriptive tools of the charge distribution within hemes. We used these methods as others [41, 87, 88] to explore the amount of charge redistribution in heme, ferrous or ferric through complexation with the model ligand CO. Both approaches provide similar trends. First the local charge on the iron atom (Table 6 and Table 7 ) in $\left[\mathrm{Fe}^{\mathrm{II}} \mathrm{Heme}-\mathrm{CO}\right]$ and $\left[\mathrm{Fe}^{\mathrm{III}} \mathrm{Heme}-\mathrm{CO}\right]^{+}$largely 
departs from the formal Fe oxidation states, either $+\mathrm{II}$ or $+\mathrm{III}$ and shows reduced difference between them. Indeed, the charge on the ferric Fe atom in [Fe $\left.{ }^{\mathrm{II}} \mathrm{Heme}-\mathrm{CO}\right](S=0)$ shows only a 0.35 e- excess with respect to $\left[\mathrm{Fe}^{\mathrm{III}} \mathrm{Heme}-\mathrm{CO}\right]^{+}(S=3 / 2)$ and this difference is solely observed in the absence of spin flip in ferric heme. For the unphysical $\left[\mathrm{Fe}^{\mathrm{III}} \mathrm{Heme}-\mathrm{CO}\right]^{+}(S=1 / 2)$ the difference is 0.09 and for the uncomplexed $\left[\mathrm{Fe}^{\mathrm{II}} \mathrm{Heme}\right]$ ferrous and ferric $\left[\mathrm{Fe}^{\mathrm{III}} \mathrm{Heme}\right]^{+}$hemes, the difference is -0.1 . This was already noted by Liao et al.[87] who found a small difference of 0.16 e- for the effective Mulliken populations of the $\mathrm{Fe}(3 \mathrm{~d}+4 \mathrm{~s})$ shells of 7.04 and 6.88 respectively for $\left[\mathrm{Fe}^{\mathrm{II}} \mathrm{TPP}\right]$ and $\left[\mathrm{Fe}^{\mathrm{III}} \mathrm{TTP}\right]^{+}$representing a +0.16 charge difference. Therefore, the former 0.35 e- excess between $\left[\mathrm{Fe}^{\mathrm{II}} \mathrm{Heme}-\mathrm{CO}\right](S=0)$ and $\left[\mathrm{Fe}^{\mathrm{III}} \mathrm{Heme}-\mathrm{CO}\right]^{+}(S=3 / 2)$ may be due to a different coupling of $\mathrm{Fe}$ atom orbitals with the porphyrin cycle. These facts underline the fact that the porphyrin is a charge reservoir and there is a strong charge compensation from the porphyrin ligand to the metal cation resulting in a positive charge largely spread over the porphyrin ligand (in the blue and green regions in Figure 25, along the values in Table 6). It suggests the many similarities in behaviour for the coordinating $\mathrm{Fe}^{\mathrm{II}}$ and $\mathrm{Fe}^{\mathrm{III}}$ atoms and if one examines the detailed distributions on the Fe atom in low spin $(S=0)$ for ferrous heme and $(S=1 / 2)$ for ferric heme in Table 7 , they are remarkably similar.

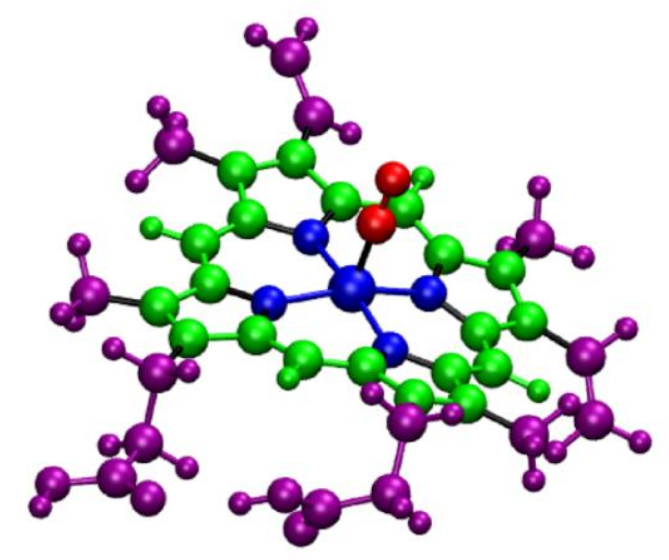

Figure 25: Ball-and-stick representation of Fe-Protoporphyrin IX coordinating CO. Atoms are classified in four groups as illustrated by the use of 4 different colours (Fe-4N in blue, $\mathrm{CO}$ in red, Porphyrin in green and Substituents in violet). The charges of each group are given in Table 6

The spin charges obtained by the analysis of the difference between the electron densities of alpha and beta electrons highlight the preferential localization of unpaired electrons on the $\mathrm{Fe}$ 4N core (2.28 based on the iterative Hirshfeld analysis), and for a large part on the porphyrin (resp. 0.43), in $S=3 / 2$ ferric hemes. 
Table 6: electronic structure analyses of heme ligated to CO in ferrous and ferric states obtained via two different approaches, namely the iterative Hirshfeld procedure and the Natural Population analyses. Analyses done on optimized structures with the OPTX-PBE XC energy functional.

\begin{tabular}{lccc|ccc}
\hline & \multicolumn{3}{c|}{ Iterative Hirshfeld } & \multicolumn{3}{c}{ NPA } \\
\hline$\left[\mathrm{Fe}^{\mathrm{II} / \mathrm{III}} \text { Heme-CO }\right]^{0 /+}$ & $q$ Ferrous & $q$ Ferric & $\begin{array}{c}\text { spin } \\
(\text { Ferric })\end{array}$ & $q$ Ferrous & $q$ Ferric & $\begin{array}{c}\text { spin } \\
\text { Fe-4N }\end{array}$ \\
\hline $\mathrm{CO}$ & -0.89 & -0.80 & 2.28 & -1.53 & -1.51 & 1.72 \\
Porphyrin & -0.09 & -0.10 & 0.14 & 0.11 & -0.05 & 0.10 \\
Substituents & 1.24 & 1.81 & 0.43 & 1.26 & 2.11 & 1.10 \\
\hline
\end{tabular}

In Table 7 we compare, the detailed Natural atomic populations for [ $\left.\mathrm{Fe}^{\mathrm{II}} \mathrm{Heme}\right](S=1)$ and the $\left[\mathrm{Fe}^{\mathrm{II}} \mathrm{Heme}-\mathrm{CO}\right](S=0)$ complex. For the free heme, the $4 \mathrm{~s}$ state is only populated by $0.27 \mathrm{e}-$, indicative of a $\mathrm{Fe}^{\mathrm{II}}$ state, while the $\mathrm{Fe}\left(3 \mathrm{~d}_{\mathrm{x} 2-\mathrm{y} 2}\right)$ orbital is populated by $(0.65 / 0.8)$ e-. This orbital, which is typically high in energy, is found to mix with the neighbouring $\mathrm{N}$ atom p orbitals and its energy lowered [41] thereby accepting population from $\mathrm{N}$ atoms. In the free triplet [Fe $\mathrm{Fe}^{\mathrm{II}}$ Heme] the populations of $3 \mathrm{~d}_{\mathrm{xy}}$ (1.76), 3dxz (1.07) and 3dyz (1.84) follow that described in Figure 4 for $S=1$ ferrous porphyrin.

In the ferrous state, the $3 \mathrm{~d}_{z^{2}}$ and $3 \mathrm{~d}_{\mathrm{yz}}$ atomic orbitals are depopulated upon complexation by $\mathrm{CO}$ by 0.2 and 0.18 e-, respectively. The spin flip induces a unit charge departure from $\mathrm{Fe}$ $\left(3 d_{z^{2}}\right)$ partly compensated by $\sigma \sigma$ donation from CO. In turn $3 d_{x z}$ gains charge from the spin flip but donates to $\mathrm{CO}\left(\pi^{*}\right), 0.56 \mathrm{e}-$. The net transfer is $0.46 \mathrm{e}$ - and $\mathrm{Fe}\left(3 \mathrm{~d}_{\mathrm{xy}}\right)$ also gains 0.13 in electronic population.

Table 7: Natural Bonding Orbital analysis of occupation of the metal cation in $3 \mathrm{~d}$ and $4 \mathrm{~s}$ shells. Calculations have been carried out in the standard orientation for which the Fe-CO bond almost is aligned with the z-axis. The $\mathrm{x}$ and $\mathrm{y}$ axis are aligned along the Fe-Np bonds. NBO analyses obtained with the OPTX-PBE or the B3LYP (in brackets) XC functionals.

\begin{tabular}{lccccccc}
\hline & spin & $4 \mathrm{~s}$ & $3 \mathrm{~d}_{\mathrm{xy}}$ & $3 \mathrm{~d}_{\mathrm{xz}}$ & $3 \mathrm{~d}_{\mathrm{yz}}$ & $3 \mathrm{~d}_{\mathrm{x}}^{2}{ }^{2}{ }^{2}$ & $3 \mathrm{~d}_{z^{2}}$ \\
\hline$\left[\mathrm{Fe}^{\mathrm{II}} \mathrm{Heme}\right]$ & $S=1$ & 0.27 & 1.76 & $1.07(0.86)$ & 1.84 & 0.65 & $1.14(0.81)$ \\
{$\left[\mathrm{Fe}^{\mathrm{II}} \mathrm{Heme}-\mathrm{CO}\right]$} & $S=0$ & 0.27 & 1.89 & 1.63 & 1.66 & 0.80 & $0.94(0.82)$ \\
{$\left[\mathrm{Fe}^{\mathrm{III}} \mathrm{Heme}\right]^{+}$} & $S=3 / 2$ & 0.27 & 1.07 & 1.67 & 1.72 & 0.87 & 1.23 \\
{$\left[\mathrm{Fe}^{\mathrm{III}} \mathrm{Heme-CO}\right]^{+}$} & $S=3 / 2$ & 0.26 & 1.08 & 1.68 & 1.72 & 0.87 & 1.23 \\
{$\left[\mathrm{Fe}^{\mathrm{III}} \text { Heme-CO }\right]^{+}$} & $S=1 / 2$ & 0.26 & 1.72 & 1.59 & 1.70 & 0.84 & 0.99 \\
\hline
\end{tabular}


In contrast, complexation in the ferric $\left[\mathrm{Fe}^{\mathrm{III}} \mathrm{Heme}-\mathrm{CO}\right]^{+}$complex does not produce a measurable impact on the electron distribution; as detected by the NBO analysis, only a 3 times weaker bond is observed. It is striking to note that the detailed electron distribution on the $\mathrm{Fe}(3 \mathrm{~d})$ orbitals either in the ferric or ferrous $\mathrm{CO}$ complexes is almost the same for low spin cases $S=1 / 2$ or $S=0$ (Table 7) ; therefore the spin flip to $S=1 / 2$, which is energetically inaccessible in the ferric case (Figure $7 b$ ) cannot be operative for $\mathrm{CO}$ ligation to ferric heme.

\section{Perspective}

Binding of dioxygen to ferrous heme or to ferric heme are remarkably different. The complexation in sixth-coordination of $\mathrm{O}_{2}$ to ferrous heme is the source of life via the affinity of the ferrous hemoprotein, strikingly distinct from that of ferric protein. However ferrous and ferric hemes share the same ligation mechanisms but different conditions are encountered in their ligation to small molecules.

In this view, the scope of the present review has been to examine the gradual buildup of ligation of ferrous and ferric hemes in vacuo to derive their common behavior and the underlying binding mechanisms using their bond energy as the characterizing parameter. Indeed, in specific experimental conditions, such as the gas phase, lower temperatures, the binding of ferric hemes with small ligands in either fifth- or sixth-coordination can be completed and compared with corresponding ferrous heme ligations. In fifth coordination the binding energies of $\mathrm{O}_{2}$ and $\mathrm{CO}$ are smaller by a factor of 3-4 in the ferric case as compared to the ferrous case and become very weak in six-coordinate ferric heme unlike ferrous heme. On the other hand, NO binds equivalently ferrous and ferric hemes, while water binds more strongly ferric (as in cytochrome $\mathrm{P} 450$ [89]) than ferrous hemes in both $5^{\text {th }}$ and $6^{\text {th }}$ coordination. Many situations are encountered in ferrous and ferric hemes that, however, share the same mechanisms.

As an example, NO ligates ferrous and ferric hemes through a similar spin flip to low spin potentials, from their initial spin states. In the ferrous case, a spin flip occurs to the low spin $\mathrm{Fe}^{\mathrm{II}}$ potential ( $S=1 / 2$ total spin), while in ferric heme this potential is attained after an 'electron transfer' from NO, reaching a $\left[\mathrm{Fe}^{\mathrm{II}} \mathrm{Heme}-\mathrm{NO}\right]^{+}(S=0)$ potential. Although the accepting orbital on the $\mathrm{Fe}$ II/III atom is the same, $\mathrm{Fe}\left(3 \mathrm{~d}_{z^{2}}\right)$, the donating ones on NO differ and this causes a bent ligation for ferrous heme and a linear one for ferric heme. In this situation, NO, a strong ligand in the organometallic scale, finds optimum binding conditions in low spin respectively for ferrous heme $S=1 / 2$ (total spin) and $S=0$ for ferric heme through the empty $\mathrm{Fe}\left(3 \mathrm{~d}_{z^{2}}\right)$ orbital. 
Conversely, the same lowering of the low spin state is not observed for ferric heme with other ligands in the calculations represented in Figure 7 b, where the intermediate spin 3/2 (or 5/2 on the fifth coordinated $\mathrm{O}_{2}$ complex) is the lowest energy structure in complexed and uncomplexed species. Binding with these ligands then results from a similar donation and back donation mechanism but with a different matching between donor and acceptor levels. Indeed, calculations have shown that levels connected to $\mathrm{Fe}(3 \mathrm{~d})$ are lower by $2 \mathrm{eV}$ in ferric porphyrins as compared to ferrous porphyrins, as seen in Figure 26 adapted from ref [87].

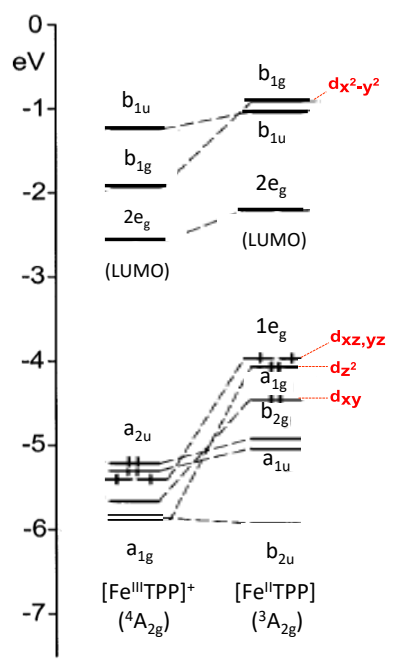

Figure 26: Comparative outer orbital energy levels in [Fe TPP] and [Fe TPP $]^{+}$[87], adapted with permission from ref[87].

$6^{\text {th }}$ coordination of ferric hemes with imidazoles is much weaker than $5^{\text {th }}$ coordination, an effect that seems different in 6 coordinated ferrous porphyrins and also with a cysteinate $5^{\text {th }}$ proximal ligand. Therefore, the investigation in the gas phase of ferrous $6^{\text {th }}$ ligated systems and ferric cysteinate complexes represents an important goal.

The present results show the achievements and the road to come in order to compare the mechanisms as they can be deduced from experiments and as they show from calculations.

Here, it is favourable to compare experimental binding energies with those calculated by hybrid DFT, as discussed. It is seen that some mechanisms can be delineated through the calculation of the changes in electron distributions: there is presently some agreement with the common belief of the emptying of the Fe (4s) orbitals at the benefit of $N(2 p)$ and Fe $\left(3 d_{x 2-y 2}\right)$. What seems at stake is the remaining difference in the Fe (3d) occupation numbers in ferrous and ferric hemes and more importantly the position of low spin states in complexed systems. 
Finally, while fifth coordination can be reasonably understood in the present status, the more precise description and understanding of five coordinate systems by gas phase methods is an attractive challenge.

\section{Acknowledgements}

N.S and B.S. acknowledge the financial support of "Investissements d'Avenir du LabEx PALM (ANR-10-LABX-0039-PALM)". The authors are thankful to Pr Simonetta Fornarini for her active interest in this study. We also acknowledge extended discussions with Pr Reza Omidyan (University of Isfahan), Mohammad Aarabi during his PhD with Pr Omidyan on the structure and energy of heme complexes and Dr S.Soorkia at ISMO.

\section{References}

[1]. N. Lane, Life Ascending: The Ten Great Inventions of Evolution. (W. W. Norton \& Company, NY,NY, 2010).

[2]. https://en.wikipedia.org/wiki/Porphyrin, edited by wikipedia (wikipedia, 2020).

[3]. G. W. Hodgson and B. L. Baker, 1969 Geochim. Cosmochim. Acta 33: 943.

[4]. $\quad$ K. S. Suslick and T. J. Reinert, 1985 J. Chem. Educ. 62: 974.

[5]. L. Pauling and C. D. Coryell, 1936 Proc. Natl. Acad. Sci. U. S. A. 22: 210.

[6]. A. Ikezaki, Y. Ohgo and M. Nakamura, 2009 Coord. Chem. Rev. 253: 2056.

[7]. J. H. Wang, 1970 Acc. Chem. Res. 3: 90.

[8]. J. P. Collman, R. Boulatov, C. J. Sunderland and L. Fu, 2004 Chem. Rev. 104: 561.

[9]. V. K. K. Praneeth, C. Näther, G. Peters and N. Lehnert, 2006 Inorg. Chem. 45: 2795.

[10]. H. Chen, M. Ikeda-Saito and S. Shaik, 2008 J. Am. Chem. Soc. 130: 14778.

[11]. O. Hampe, T. Karpuschkin, M. Vonderach, P. Weis, Y. Yu, L. Gan, W. Klopper and M. M. Kappes, 2011 Phys. Chem. Chem. Phys. 13: 9818.

[12]. G. Feraud, M. Broquier, C. Dedonder-Lardeux, G. Gregoire, S. Soorkia and C. Jouvet, 2014 Phys. Chem. Chem. Phys. 16: 5250.

[13]. F. Angelelli, B. Chiavarino, M. E. Crestoni and S. Fornarini, 2005 J. Am. Soc. Mass. Spectrom. 16: 589.

[14]. M. K. Lykkegaard, H. Zettergren, M.-B. S. Kirketerp, A. Ehlerding, J. A. Wyer, U. Kadhane and S. B. Nielsen, 2009 J. Phys. Chem. A. 113: 1440.

[15]. M. Neumaier, F. Weigend, O. Hampe and M. M. Kappes, 2005 J. Chem. Phys. 122: 104702.

[16]. O. Chen, S. Groh, A. Liechty and D. P. Ridge, 1999 J. Am. Chem. Soc. 121: 11910.

[17]. L. Ferrand, S. Soorkia, G. Gregoire, M. Broquier, B. Soep and N. Shafizadeh, 2015 Phys. Chem. Chem. Phys. 17: 25693.

[18]. R. C. Dunbar and T. B. McMahon, 1998 Science 279: 194.

[19]. J. V. Dugan Jr, J. H. Rice and J. L. Magee, 1969 Chem. Phys. Lett. 3: 323.

[20]. A. T. Blades and P. Kebarle, 2006 J. Phys. Chem. A. 110: 12055. 
[21]. T. Archipov, J. Kirkland, K. D. Vogiatzis, A. Steiner, G. Niedner-Schatteburg, P.

Weis, K. Fink, O. Hampe and M. M. Kappes, 2018 J. Phys. Chem. A. 122: 4357.

[22]. B. Chiavarino, M. E. Crestoni, S. Fornarini and C. Rovira, 2008 Inorg. Chem. 47: 7792.

[23]. T. Karpuschkin, M. M. Kappes and O. Hampe, 2013 Angew. Chem. Int. Ed. 52: 10374.

[24]. R. L. Woodin and J. L. Beauchamp, 1978 J. Am. Chem. Soc. 100: 501.

[25]. S. Dillinger, J. Lang and G. Niedner-Schatteburg, 2017 J. Phys. Chem. A 121: 7191.

[26]. J. A. Wyer and S. B. Nielsen, 2010 J. Chem. Phys. 133: 084306.

[27]. N. Lehnert, W. R. Scheidt and M. W. Wolf, in Nitrosyl Complexes in Inorganic Chemistry, Biochemistry and Medicine II, edited by D. M. P. Mingos (Springer Berlin Heidelberg, Berlin, Heidelberg, 2014), pp. 155.

[28]. T. G. Spiro, A. V. Soldatova and G. Balakrishnan, 2013 Coord. Chem. Rev. 257: 511.

[29]. J. N. Harvey, 2006 Annual Reports Section "C" (Physical Chemistry) 102: 203.

[30]. M. Radoń and K. Pierloot, 2008 J. Phys. Chem. A. 112: 11824.

[31]. G. Li Manni and A. Alavi, 2018 J. Phys. Chem. A 122: 4935.

[32]. A. Becke, 1993 J. Chem. Phys 98: 1372.

[33]. Frank Weinhold and C. R. Landis, in Valency and bonding : a natural bond orbital donor-acceptor perspective (Cambridge University Press, Cambridge, UK ; New York, 2005), pp. 749.

[34]. R. Weiss, A. Gold and J. Terner, 2006 Chem. Rev. 106: 2550.

[35]. Z. Zhou, M. Shen, C. Cao, Q. Liu and Z. Yan, 2012 Chemistry - A European Journal 18: 7675 .

[36]. Y. Ling and Y. Zhang, 2009 J. Am. Chem. Soc. 131: 6386.

[37]. C. J. Hu, C. E. Schulz and W. R. Scheidt, 2015 Dalton Transactions 44: 18301.

[38]. J. A. Wolny, V. Schünemann, Z. Németh and G. Vankó, 2018 Comptes Rendus Chimie 21: 1152 .

[39]. A. S. Brill and R. J. P. Williams, 1961 Biochem. J. 78: 246.

[40]. C. Duboc and M. Gennari, in Spin States in Biochemistry and Inorganic Chemistry, eds M. Swart, M. Costas (John Wiley \& Sons, Ltd 2015), pp. 59.

[41]. M. E. Ali, B. Sanyal and P. M. Oppeneer, 2012 J.Phys.Chem. B 116: 5849.

[42]. C. Rovira, K. Kunc, J. Hutter, P. Ballone and M. Parrinello, 1998 Int. J. Quantum Chem. 69: 31.

[43]. M.-S. Liao, M.-J. Huang and J. D. Watts, 2013 J.Phys.Chem. B 117: 10103.

[44]. M. C. Durrant, 2014 Dalton Trans. 43: 9754.

[45]. M.-S. Liao, M.-J. Huang and J. D. Watts, 2010 J. Phys. Chem. A. 114: 9554.

[46]. J. Mispelter, M. Momenteau and J. M. Lhoste, 1977 Mol. Phys. 33: 1715.

[47]. M. Fang, S. R. Wilson and K. S. Suslick, 2008 J. Am. Chem. Soc. 130: 1134.

[48]. B. Chiavarino, M. E. Crestoni, S. Fornarini and C. Rovira, 2007 Chem.-Eur. J. 13: 776.

[49]. W. R. Scheidt and C. A. Reed, 1981 Chem. Rev. 81: 543.

[50]. M. Nakamura, 2006 Coord. Chem. Rev. 250: 2271.

[51]. B. J. Kennedy, G. Brain and K. S. Murray, 1984 Inorg. Chim. Acta 81: L29.

[52]. H. Nasri, M. K. Ellison, B. Shaevitz, G. P. Gupta and W. R. Scheidt, 2006 Inorg. Chem. 45: 5284.

[53]. N. Shafizadeh, S. Soorkia, G. Grégoire, M. Broquier, M.-E. Crestoni and B. Soep, 2017 Chemistry - A European Journal 23: 13493.

[54]. M. Aarabi, S. Soorkia, G. Gregoire, M. Broquier, A. de la Lande, B. Soep, R. Omidyan and N. Shafizadeh, 2019 Phys. Chem. Chem. Phys. 21: 21329. 
[55]. M. Aarabi, R. Omidyan, S. Soorkia, G. Grégoire, M. Broquier, M.-E. Crestoni, A. de la Lande, B. Soep and N. Shafizadeh, 2019 Phys. Chem. Chem. Phys. 21: 1750.

[56]. W. A. Eaton and R. M. Hochstrasser, 1968 J. Chem. Phys. 49: 985.

[57]. J. A. Wyer and S. B. Nielsen, in Photophysics of Ionic Biochromophores, edited by S. Brøndsted Nielsen and J. A. Wyer (Springer Berlin Heidelberg, Berlin, Heidelberg, 2013), pp. 117.

[58]. J. A. Wyer and S. B. Nielsen, 2012 Angew. Chem., Int. Ed. Engl. 51: 10256.

[59]. V. K. K. Praneeth, F. Paulat, T. C. Berto, S. D. George, C. Näther, C. D. Sulok and N. Lehnert, 2008 J. Am. Chem. Soc. 130: 15288.

[60]. G. Gregoire, J. Velasquez and M. A. Duncan, 2001 Chem. Phys. Lett. 349: 451.

[61]. S. Ishizaka, T. Wada and N. Kitamura, 2009 Photoch. Photobio Sci. 8: 562.

[62]. W. J. Bowen, 1949 J Biol Chem 179: 235.

[63]. M. K. Lykkegaard, A. Ehlerding, P. Hvelplund, U. Kadhane, M.-B. S. Kirketerp, S. B. Nielsen, S. Panja, J. A. Wyer and H. Zettergren, 2008 J. Am. Chem. Soc. 130: 11856.

[64]. H. Ogoshi, H. Sugimoto, E.-i. Watanabe, Z.-i. Yoshida, Y. Maeda and H. Sakai, 1981 Bull. Chem. Soc. Jpn. 54: 3414.

[65]. W. R. Scheidt, D. K. Geiger, Y. J. Lee, C. A. Reed and G. Lang, 1985 J. Am. Chem. Soc. 107: 5693.

[66]. F. Lanucara, D. Scuderi, B. Chiavarino, S. Fornarini, P. Maitre and M. E. Crestoni, 2013 J.Phys.Chem.Lett. 4: 2414.

[67]. B. Chiavarino, M. E. Crestoni, S. Fornarini, F. Lanucara, J. Lemaire, P. Maître and D. Scuderi, 2008 ChemPhysChem 9: 826.

[68]. M. Gouterman, G. H. Wagnière and L. C. Snyder, 1963 J. Mol. Spectrosc. 11: 108.

[69]. M. Zerner, Gouterma.M and Kobayash.H, 1966 Theor. Chim. Acta 6: 363.

[70]. M. Zerner and Gouterma.M, 1966 Theor. Chim. Acta 4: 44.

[71]. M. S. Liao and S. Scheiner, 2002 J. Chem. Phys. 116: 3635.

[72]. M. E. Casida and D. Chong, 1995 Computational Chemistry: Reviews of Current Trends.

[73]. M. Hoshino, L. Laverman and P. C. Ford, 1999 Coord. Chem. Rev. 187: 75.

[74]. L. E. Laverman and P. C. Ford, $2001 \mathrm{~J}$. Am. Chem. Soc. 123: 11614.

[75]. A. Wanat, M. Wolak, Ł. Orzeł, M. Brindell, R. van Eldik and G. Stochel, 2002 Coord. Chem. Rev. 229: 37.

[76]. I. Ivanović-Burmazović and R. van Eldik, 2008 Dalton Transactions: 5259.

[77]. P. C. Ford and I. M. Lorkovic, 2002 Chem. Rev. 102: 993.

[78]. C. Rovira, K. Kunc, J. Hutter, P. Ballone and M. Parrinello, 1997 J. Phys. Chem. A 101: 8914.

[79]. N. Strickland and J. N. Harvey, 2007 J.Phys.Chem. B 111: 841.

[80]. L. E. Goodrich, F. Paulat, V. K. K. Praneeth and N. Lehnert, 2010 Inorg. Chem. 49: 6293.

[81]. B. Chiavarino, M. E. Crestoni and S. Fornarini, 2014 Croat. Chem. Acta 87307.

[82]. J. J. Weiss, 1964 Nature 202: 83.

[83]. D. R. Evans and C. A. Reed, 2000 J. Am. Chem. Soc. 122: 4660.

[84]. A. Abdurahman and T. Renger, 2009 J. Phys. Chem. A. 113: 9202.

[85]. K. Wiberg, 1985 J. Chem. Phys 83: 735.

[86]. P. Bultinck, C. Van Alsenoy, P. W. Ayers and R. Carbó-Dorca, 2007 J. Chem. Phys. 126: 144111.

[87]. M. S. Liao and S. Scheiner, 2002 J. Chem. Phys. 117: 205.

[88]. A. R. Groenhof, M. Swart, A. W. Ehlers and K. Lammertsma, 2005 J. Phys. Chem. A. 109: 3411 . 
[89]. S. Shaik, S. Cohen, Y. Wang, H. Chen, D. Kumar and W. Thiel, 2010 Chem. Rev. 110: 949. 